\title{
Consumption Risk Sharing with Private Information and Limited Enforcement*
}

\author{
Tobias Broer \\ IIES, Stockholm University
}

Marek Kapička

CERGE-EI

and UC Santa Barbara

\author{
Paul Klein \\ Simon Fraser University
}

February 26, 2015

\begin{abstract}
In this paper, we study consumption risk sharing when individual income shocks are persistent and not publicly observable, and individuals can default on contracts at the price of financial autarky. We find that, in contrast to a model where the only friction is limited enforcement, our model has observable implications that are similar to those of an Aiyagari (1994) self-insurance model and therefore broadly consistent with empirical observations. However, some of the implied effects of changes in policy or the economic environment are noticeably different in our model compared to self-insurance.
\end{abstract}

J.E.L Codes: D8, E6

Keywords: risk sharing, private information, limited enforcement

\footnotetext{
*We thank Árpád Ábrahám, Orazio Attanasio, Per Krusell, Nicola Pavoni, José-Víctor Ríos-Rull and seminar participants at the New Economic School (Moscow), Arizona State University, the University of Southampton, the Hebrew University of Jerusalem, the European University Institute, the University of Edinburgh, the EIEF (Rome), the University of Washington, the University of Tel Aviv, and the NBER Summer Institute for their comments. Klein also thanks LAEF for its generous hospitality. This paper has previously circulated under the title "Consumption risk sharing with private information when earnings are persistent".
} 


\section{Introduction}

This paper studies the quantitative implications of a general equilibrium model of consumption risk sharing where there is private information about earnings (which are persistent) and enforcement of contracts is limited in the sense that consumers can walk away from a dynamic contract, giving rise to period-by-period participation constraints as well as truth-telling constraints. Our main finding is that the empirically testable implications of our model are similar-though not identicalto those of a Bewley (1977) and Aiyagari (1994) model, and are therefore broadly in line with key features of the data. This contrasts with the implications of models where the only friction is limited enforcement, as in Krueger and Perri (2006). On the other hand, the response to an introduction of a compulsory social insurance program financed by an income tax is similar to the Krueger-Perri model, and in contrast to the Bewley-Aiyagari model.

The spirit of our exercise is quite similar to that of Krueger and Perri (2006) and Krueger and Perri (2011). We explicitly model the frictions that lead to imperfect risk sharing, as opposed to simply assuming that markets are exogenously incomplete. The question is, how do the frictions affect the implied effects of policy interventions or changes in the environment? It seems to us that this question needs to be answered in the context of a model with observable implications which are broadly in line with the facts. In this respect, as documented by Broer (2013), models with only limited enforcement fall short. Specifically, such models imply a much stronger left skew of log consumption than of log earnings, and that consumption responds extremely asymmetrically to earnings increases and decreases; both these features are strongly counterfactual. This feature comes from the fact that, in these models, consumption always drifts down when the participation constraint does not bind, and then jumps up when it does bind, which happens whenever earnings increase sufficiently. This gives rise to an extreme and very counterfactual degree of left skewness in both consumption and log consumption.

In contrast, our model with private information and limited enforcement (PILE 
model) implies that consumption will gradually drift up when income is high as well as gradually drift down when income is low. This means that our model avoids the counterfactual implications of limited enforcement (LE) models such as those in Krueger and Perri (2006) or Krueger and Uhlig (2006). Indeed, the observable implications of our model are quite similar, though not identical, to those of the self insurance (SI) models of Bewley (1977) and Aiyagari (1994). ${ }^{1}$ In this sense our model provides a more rigorous foundation of this property than SI models do. Though our model is not able to deliver log-normality of consumption, it avoids the counterfactual implication that log consumption is much more skewed to the left than log earnings are.

In order to compare the implications of our model with those of SI and LE models in more detail, we examine the consequences of the following interventions: reduction in idiosyncratic risk, introduction of a social insurance program financed by income taxes, and introduction of a social insurance program financed by consumption taxes. Our main findings are as follows. First, consumption volatility in PILE model decreases in all our exercises that involve an exogenous decrease in idiosyncratic risk or social insurance financed by a consumption tax. In fact the implications of these interventions in the context of our model turn out to be very similar to those in an SI model. In other words, when considering these interventions, our model does not exhibit the property discussed in Krueger and Perri (2011), where lower income volatility can cause a rise in consumption risk by making the punishment of default—financial autarky-less severe. Second, we show how this result changes in the case of a social insurance program financed by income taxes, where our model is even more pessimistic than Krueger and Perri (2011): public insurance always crowds out private insurance at least by the same amount. This is because truth-telling constraints make public and private insurance perfect substitutes whenever income is unobserved both by the government and by insurance providers. Moreover, because public insurance makes the outside option of financial autarky more attractive, in contrast to private insurance, a rise in in-

\footnotetext{
${ }^{1}$ See also Huggett (1993), Huggett (1997), and many others.
} 
come redistribution typically implies a rise in consumption risk by more than fully crowding-out private insurance.

Our theoretical contribution is to characterize the properties of the equilibrium in our model. In this respect, we build on the results of Thomas and Worrall (1990) and Fernandes and Phelan (2000) but go several steps further. Specifically, we show that the dynamic program for solving for the optimal insurance contract can be separated into two subproblems, each solving for the optimal insurance contract conditional on the current shock. The subprograms have two notable properties. First, they are completely independent of each other, and this simplifies the computation. Second, conditional on the current shock, the allocations are independent of the previous period shock. This conclusion may seem surprising, given that the solution to the Fernandes-Phelan dynamic contract exhibits dependence on the previous shock. Our formulation differs, however in one critical aspect: in our environment, with only two income values, we can dispense with the notion of the promised utility of the truthteller and promised utility of the deviator (threat utility), and simply keep track of the promised utility for the low and high types. That turns out to be important, because the low and high types are obviously independent of the previous shock, but the identity of the truthteller and of the deviator depends on it. That is the only dependence on the previous shock. Appropriately redefining the states thus simplifies the problem. We also provide a sharper characterization of the state space (the set of feasible vectors of promised utilities). In the presence of the participation constraints, we provide a simple expression for the bounds of the state space, and provide a sharp characterization of the lower left-hand corner of the feasible set. Moreover, we show that in the absence of limited enforcement constraints, the state space is a convex cone whose bounds we characterize analytically.

In addition to the papers mentioned already, our work is also related to the work of Allen (1985) and Cole and Kocherlakota (2001) who study the efficient allocations in economies similar to ours under the assumption that individuals can privately save. 
They show that under certain conditions the efficient allocations can be decentralized in a competitive equilibrium with a risk-free bond, and thus provide explicit microfoundations for the Bewley-Aiyagari model. ${ }^{2}$ We view our work as complementary to theirs. Our results show that hidden savings may be sufficient, but not necessary, to obtain quantitatively similar results in dynamic private information economies and Bewley-Aiyagari economies.

Many recent papers study efficient allocations in related dynamic environments, where the agents have private information about their productivity rather than incomes, as in Mirrlees (1971). For example, Farhi and Werning (2011) and Golosov et al. (2012) consider a dynamic Mirrlees economy where private productivity shocks are persistent. The interpretation of efficient allocations is different from ours, however, in that they are typically interpreted as optimal capital and income taxes, while we focus on private insurance contracts, which may or may not lead to efficient allocations. On the technical side, these papers typically use the first-order approach (see Kapička, 2013 and Pavan et al., 2014). Although potentially useful also in our environment, we do not use the first-order approach in this paper.

The paper is organized as follows. Section 2 lays out the model framework and establishes some important theoretical results. In Section 3, we describe how to characterize the optimal insurance contract recursively in the case where earnings can take only two possible values. Section 4 compares the observable implications of our model to those of other models of consumption risk sharing and to key features of US micro-data. Section 5 considers the effects of changes in the environment or policy. Section 6 concludes.

\footnotetext{
${ }^{2}$ See also Attanasio and Pavoni (2011), Golosov and Tsyvinski (2007) and Ales and Maziero (2009) for further results.
} 


\section{The PILE Economy}

We analyze an economy with three types of agents: a continuum of households (agents) facing idiosyncratic shocks, competitive insurance providers (principals), and a government. The economy features both private information (incentive) constraints and limited enforcement constraints, and we will henceforth call it the PILE ("private information with limited enforcement") economy.

Household. Each household lives forever in discrete time. The households maximize the expected utility of consumption

$$
\mathbb{E}\left[\sum_{t=0}^{\infty} \beta^{t} U\left(c_{t}\right)\right],
$$

where the subjective discount factor satisfies $0<\beta<1$ and where $U: \mathbb{R}_{+} \rightarrow \mathbb{R}_{-}$is increasing, differentiable, and is such that $U(c)<0$ for all $c \geq 0$ and $\lim _{c \rightarrow \infty} U(c)=$ 0 . We further restrict the utility function as follows:

Assumption 1 The function $\varphi(c):=-\frac{U^{\prime \prime}(c)}{U^{\prime}(c)} \cdot c$ is strictly positive and decreasing in $c$.

Idiosyncratic productivity shocks follow a finite-state Markov chain with state space $\left\{y^{1}, y^{2}, \ldots, y^{N}\right\}$ where $y^{1}<y^{2}<\ldots<y^{N}$, with the probability of transiting from state $i$ to state $j$ denoted by $\pi_{i j}$. We adopt the notation $\mathcal{N}=\{1,2, \ldots, N\}$ and simplify the analysis by assuming that the average shock equals one. The probability of a sequence of shocks $h^{t}=\left(i_{0}, i_{1}, \ldots, i_{t}\right)$ given an initial shock level $j$ is denoted by $\pi^{t}\left(h^{t} \mid j\right)$. The set of possible sequences $h^{t}$ is denoted by $\mathcal{N}^{t}$. The endowment shocks are private information of the agents, with the exception of the initial "seed" value $i_{-1}$, which is given and known to everyone. The amount consumed is also private information of the households. We assume, however, that all the goods consumed must be purchased through anonymous market transactions.

Each period, the households report their current shock. The report is observed both by the government and the insurance providers. We denote a history of reports 
until period $t-1$ as $h^{t-1}$ and the same history followed by a report of income $y^{i}$ as $\left(h^{t-1}, i\right)$.

Government. The government taxes income and consumption as follows. It chooses an income tax schedule $s^{y}=\left\{s_{t}^{y}\left(h^{t}\right)\right\}_{t=0}^{\infty}$, where $s_{t}^{y}\left(h^{t}\right)$ is the tax that must be paid by an agent with reported history $h^{t}$. In addition, the government imposes a proportional tax on consumption $s^{c}=\left\{s_{t}^{c}\right\}_{t=0}^{\infty}$, where $s_{t}^{c}$ is the tax rate in period $t$. The government chooses a consumption tax rate independent of individual histories. This is due to the fact that individual consumption is unobservable, but anonymous market transactions can only be taxed at a flat tax rate common to everyone. One can imagine (without explicitly modeling the idea) that agents purchase their consumption goods from many stores, none of which can observe the agents' total purchases, and each of which has many customers. In this environment, in order to collect the consumption tax, the government only needs to observe sales by each store as opposed to individual purchases, meaning that individual consumption remains private information. Throughout the paper we analyze government policies $s=\left(s^{y}, s^{c}\right)$ that are exogenously given, constrained only by the government budget constraint, specified below.

Insurance Providers. There is a large number of insurance providers, who compete with each other by offering, at time $t=0$, mutually agreeable insurance contracts with households. An insurance contract is a transfer program $\tau=\left\{\tau_{t}\left(h^{t}\right)\right\}_{t=0}^{\infty}$. The agents cannot save on their own, and so the principal's transfer, together with government policies, completely determines the consumption of an agent reporting her shock truthfully:

$$
c_{t}\left(h^{t} ; \tau_{t}, s_{t}\right)=\frac{y^{h_{t}}-s_{t}^{y}\left(h^{t}\right)+\tau_{t}\left(h^{t}\right)}{1+s_{t}^{c}} .
$$

Let $c(\tau, s)=\left\{c_{t}\left(h^{t} ; \tau_{t}, s_{t}\right)\right\}_{t=0}^{\infty}$ is a sequence of the agent's consumption, specified below. Define also $\boldsymbol{u}(\boldsymbol{\tau}, \boldsymbol{s})=\left\{u_{t}\left(h^{t} ; \tau_{t}, s_{t}\right)\right\}_{t=0}^{\infty}$ to be a sequence of period utilities, where $u_{t}\left(h^{t} ; \tau_{t}, s_{t}\right)=U\left(c_{t}\left(h^{t} ; \tau_{t}, s_{t}\right)\right)$. Henceforth, we will work with period utility rather than period consumption. 
Insurance providers evaluate a transfer policy $\tau$ according to the profit function

$$
P_{i_{-1}}(\boldsymbol{\tau})=-\sum_{t=0}^{\infty} \sum_{h^{t} \in \mathcal{N}^{t+1}} q_{t} \tau_{t}\left(h^{t}\right) \pi^{t}\left(h^{t} \mid i_{-1}\right)
$$

where $\boldsymbol{q}=\left\{q_{t}\right\}_{t=0}^{\infty}$ are the intertemporal prices of consumption. The households rank transfer policies $\tau$ according to the lifetime utility function

$$
V_{i_{-1}}(\boldsymbol{\tau}, \boldsymbol{s})=\sum_{t=0}^{\infty} \sum_{h^{t} \in \mathcal{N}^{t+1}} \beta^{t} u_{t}\left(h^{t} ; \tau_{t}, s_{t}\right) \pi^{t}\left(h^{t} \mid i_{-1}\right)
$$

Define a continuation of the transfer policy after history $h^{t}$ by

$$
\boldsymbol{\tau}\left(h^{t}\right):=\left\{\tau_{t+j}\left(\left(h^{t}, \widetilde{h}^{j}\right)\right)\right\}_{j=0}^{\infty},
$$

and a continuation of the government policy after history $h^{t}$ by

$$
\boldsymbol{s}\left(h^{t}\right):=\left\{s_{t+j}\left(\left(h^{t}, \widetilde{h}^{j}\right)\right)\right\}_{j=0}^{\infty} .
$$

It follows from the definition of $V$ that $V_{i}\left(\boldsymbol{\tau}\left(h^{t}\right), \boldsymbol{s}\left(h^{t}\right)\right)$ is the continuation lifetime utility for someone who reported $h^{t}$ and had a last period shock $i$.

Without loss of generality, it is assumed that the transfer policy induces agents to tell the truth. Consider an agent who receives income $y^{i}$, but reports $y^{j}$ instead. Her current consumption gain is $\delta_{t}^{i j}=\left(1+s_{t}^{c}\right)^{-1}\left(y^{i}-y^{j}\right)$, and the utility gain is

$$
\psi\left(u, \delta_{t}^{i j}\right)=U\left[\delta_{t}^{i j}+U^{-1}(u)\right]
$$

The function $\psi$ is nonpositive, increasing in $u$ with $\psi(0, \delta)=0$, and differentiable with $\psi^{\prime}(0, \delta)=1$. For the more relevant case of $\delta>0$ it also satisfies $\psi(-\infty, \delta)=U(\delta), \psi(u, \delta)>u$ if $u<0$ and $\psi^{\prime}(-\infty, \delta)=0$ and is, under Assumption 1, strictly convex in $u$. Following Fernandes and Phelan (2000), we impose the temporary incentive constraints, where only one period deviations are permitted. 
The temporary incentive constraint is

$$
\begin{aligned}
& u_{t}\left(\left(h^{t-1}, i\right) ; \tau_{t}, s_{t}\right)+\beta V_{i}\left[\boldsymbol{\tau}\left(\left(h^{t-1}, i\right)\right), s\left(\left(h^{t-1}, i\right)\right)\right] \\
& \geq \psi\left[u_{t}\left(\left(h^{t-1}, j\right) ; \tau_{t}, s_{t}\right)+\delta_{t}^{i j}\right]+\beta V_{i}\left[\boldsymbol{\tau}\left(\left(h^{t-1}, j\right)\right), s\left(\left(h^{t-1}, j\right)\right)\right] \\
& \quad \forall i, j \in \mathcal{N}, \forall h^{t-1} \in \mathcal{N}^{t-1}
\end{aligned}
$$

The insurance providers are fully committed to the transfer policy. On the other hand, there is limited enforcement of the contracts and the agents are free to walk away from the contract at the end of each period. ${ }^{3}$ Let $V_{i}^{\mathrm{AUT}}\left(\boldsymbol{s}\left(h^{t}\right)\right)$ be the expected utility from moving to autarky after history of reports $h^{t}$, given that the current period shock is $y^{i}$. Define $\boldsymbol{V}^{\mathrm{AUT}}(\boldsymbol{s})=\left\{V_{i}^{\mathrm{AUT}}\left(\boldsymbol{s}\left(h^{t}\right)\right)\right\}_{t \geq 0, i \in \mathcal{N}}$. In defining the value of autarky to depend on government policies we implicitly assume that the government has an advantage over the private insurance providers in that the agents cannot avoid paying their taxes even in autarky. ${ }^{4}$ To prevent the agents from walking away, the transfer policy has to satisfy the following limited enforcement constraint:

$$
V_{i}\left(\boldsymbol{\tau}\left(h^{t-1}\right), s\left(h^{t-1}\right)\right) \geq V_{i}^{\mathrm{AUT}}\left(s\left(h^{t-1}\right)\right) \quad \forall i \in \mathcal{N}, \forall h^{t-1} \in \mathcal{N}^{t}
$$

The benchmark definition of autarky is that neither consumption taxes nor income taxes can be avoided, and so agents in autarky have the expected utility given by

$$
V_{i_{-1}}^{\mathrm{AUT}}(\boldsymbol{s})=\max _{\left\{k_{j}\right\}_{j \in \mathcal{N}}} \sum_{j \in \mathcal{N}}\left[U\left(\frac{y^{j}-s_{0}^{y}\left(k_{j}\right)}{1+s_{0}^{c}}\right)+\beta V_{j}^{\mathrm{AUT}}\left(s\left(k_{j}\right)\right)\right] \pi_{i_{-1, j},},
$$

\footnotetext{
${ }^{3}$ Note that our timing seems, prima facie, to depart from the convention of previous studies, such as Krueger and Perri (2011) or Krueger and Perri (2006), that agents default after observing their income but before transfers are paid. This conventional timing assumption is natural in an environment with full information, where the main incentive to default results from the ability to avoid paying transfers in periods of high income. When income is unobserved, however, agents take the joint decision of default and reporting income. This implies agents would optimally never default before transfer payments, as reporting a low income realisation and defaulting after the corresponding transfer payments are received yields strictly higher utility. Our timing assumption imposes this optimal behaviour, thus simplifying the problem.

${ }^{4}$ History dependence enters the value of autarky only through the tax system.
} 
where $V_{i}^{\text {AUT }}\left(s\left(h^{t-1}\right)\right)$ is the continuation of the value of autarky after a history $h^{t-1}$. Note that the incentive compatibility constraint (3) does not necessarily apply in autarky, and the deviating agents may thus misreport their type. We will also consider an alternative value of autarky $V^{\text {AUT }}$ equal to minus infinity, which corresponds to a situation where agents cannot default at all. Other alternatives are possible as well.

Aggregates. In the aggregate, consumption has to equal available resources in each period, i.e.

$$
\sum_{h^{t} \in \mathcal{N}^{t+1}}\left[c_{t}\left(h^{t} ; \tau_{t}, s_{t}\right)-y^{h_{t}}\right] \pi^{t}\left(h^{t} \mid i_{-1}\right)=0 \quad \forall t \geq 0,
$$

and the government policy $s$ must satisfy the following budget constraint:

$$
\sum_{t=0}^{\infty} \sum_{h^{t} \in \mathcal{N}^{t+1}} q_{t}\left[s_{t}^{c} c_{t}\left(h^{t} ; \tau_{t}, s_{t}\right)+s_{t}^{y}\left(h^{t}\right)\right] \pi^{t}\left(h^{t} \mid i_{-1}\right)=0
$$

Equilibrium. The timing is as follows. At the beginning of period $t$, the agent observes current period earnings, makes a report to the principal, and receives (or pays) the appropriate transfer from (or to) the principal. At the end of the period, before knowing the next period's realization of earnings, the agent may choose to opt out of the contract and remain in autarky as of the next period. For a given tax policy $s$ and autarky values $V^{\mathrm{AUT}}(s)$, the competitive equilibrium is given by a transfer policy $\tau$ and prices $q$ such that (i) $\tau$ maximizes the insurance provider's profits $P_{i_{-1}}(\boldsymbol{\tau})$ subject to the incentive constraint (3) and the limited enforcement constraint (4) taking $q$ and $\boldsymbol{V}^{\mathrm{AUT}}(\boldsymbol{s})$ as given, (ii) the insurance providers yield zero profits, i.e. $P_{i_{-1}}(\boldsymbol{\tau})=0$, (iii) the resource constraint (6) holds, and (iv) the government budget constraint (7) holds. 


\subsection{The Effects of Government Policies: Theory}

As we shall now show, consumption taxes and income taxes have a very different impact on the equilibrium consumption of the agent. Unlike consumption taxes, the role of income taxes is very limited as they matter only by changing the value of autarky. Conditional on the value of autarky, income taxes do not affect the equilibrium allocation since they will be perfectly offset by the transfers specified by the optimal private insurance contract.

Proposition 1. Suppose that $\boldsymbol{\tau}$ and $\boldsymbol{q}$ is an equilibrium given tax policy $\left(\boldsymbol{s}^{y}, \boldsymbol{s}^{c}\right)$ and autarky values $\boldsymbol{V}^{\mathrm{AUT}}\left(\boldsymbol{s}^{y}, \boldsymbol{s}^{c}\right)$. Let $\tilde{\boldsymbol{s}}^{y}$ be another income tax policy. Then $\tilde{\boldsymbol{\tau}}=\boldsymbol{\tau}+\tilde{\boldsymbol{s}}^{y}-\boldsymbol{s}^{y}$ and $\boldsymbol{q}$ is an equilibrium given tax policy $\left(\tilde{\boldsymbol{s}}^{y}, \boldsymbol{s}^{c}\right)$ and autarky values $\boldsymbol{V}^{\mathrm{AUT}}\left(\boldsymbol{s}^{y}, \boldsymbol{s}^{c}\right)$.

Proof. Suppose that $\tau$ and $\boldsymbol{q}$ is a competitive equilibrium given $\left(s^{y}, s^{c}\right)$ and $V^{\mathrm{AUT}}\left(\boldsymbol{s}^{y}, \boldsymbol{s}^{c}\right)$. Consider an alternative policy $\left(\tilde{\mathbf{s}}^{y}, \boldsymbol{s}^{c}\right)$. Consumption implied by this alternative policy and a transfer policy $\tilde{\boldsymbol{\tau}}$ is

$$
c_{t}\left(h^{t} ; \tilde{\tau}_{t},\left(\tilde{s}_{t}^{y}, s_{t}^{c}\right)\right)=\frac{y^{h_{t}}-\tilde{s}_{t}^{y}\left(h^{t}\right)+\tilde{\tau}_{t}\left(h^{t}\right)}{1+s_{t}^{c}}=\frac{y^{h_{t}}-s_{t}^{y}\left(h^{t}\right)+\tau_{t}\left(h^{t}\right)}{1+s_{t}^{c}}=c_{t}\left(h^{t} ; \tau_{t},\left(s_{t}^{y}, s_{t}^{c}\right)\right) .
$$

Thus, the agents rank $\boldsymbol{\tau}$ under $\boldsymbol{s}^{y}$ identically to $\tilde{\boldsymbol{\tau}}$ under $\tilde{\boldsymbol{s}}^{y}$. In addition, if $\boldsymbol{\tau}$ satisfies (3) and (4) under $\boldsymbol{s}^{y}$ and $\boldsymbol{V}^{\mathrm{AUT}}\left(\boldsymbol{s}^{y}, \boldsymbol{s}^{c}\right)$ then $\tilde{\boldsymbol{\tau}}$ satisfies (3) and (4) under $\widetilde{\boldsymbol{s}}^{y}$ and $\boldsymbol{V}^{\mathrm{AUT}}\left(\boldsymbol{s}^{y}, \boldsymbol{s}^{c}\right)$. The insurance provider's profits are

$$
\begin{aligned}
P_{i_{-1}}(\tilde{\boldsymbol{\tau}}) & =-\sum_{t=0}^{\infty} \sum_{N^{t+1}} q_{t} \tilde{\tau}_{t}\left(h^{t}\right) \pi^{t}\left(h^{t} \mid i_{-1}\right) \\
& =P_{i_{-1}}(\boldsymbol{\tau})-\sum_{t=0}^{\infty} \sum_{\mathcal{N}^{t+1}} q_{t} \frac{\tilde{s}_{t}^{y}\left(h^{t}\right)-s_{t}^{y}\left(h^{t}\right)}{1+s_{t}^{c}} \pi^{t}\left(h^{t} \mid i_{-1}\right) \\
& =P_{i_{-1}}(\boldsymbol{\tau}),
\end{aligned}
$$

where the last equality follows from the government budget constraint (7) and equality between $c\left(\tau,\left(s^{y}, s^{c}\right)\right)$ and $c\left(\tilde{\tau},\left(\tilde{s}^{y}, s^{c}\right)\right)$. Hence, the insurance providers rank $\tau$ under $s^{y}$ identically to $\tilde{\tau}$ under $\tilde{s}^{y}$. Moreover, if $\tau$ yields zero profits under $s^{y}$ then $\tilde{\tau}$ yields zero profits under $\tilde{s}^{y}$. Since $c=\tilde{c}$, the resource constraint continues to hold. Hence, $\tilde{\tau}$ and $q$ is an equilibrium given $\left(\tilde{s}^{y}, s^{c}\right)$ and $V^{\mathrm{AUT}}\left(\boldsymbol{s}^{y}, \boldsymbol{s}^{c}\right)$. 
The result thus shows that direct effects on consumption are perfectly offset by the equilibrium insurance policy. In this sense, the government is subject to the same private information friction as are the private insurance providers. The income tax affects the economy only indirectly, through changes in the autarky values. The indirect effects will in general be nontrivial. If, however, $V^{\mathrm{AUT}}$ is minus infinity, then the enforcement constraints are never binding, and the indirect effects are zero. Equilibrium consumption is then independent of the income tax policy.

To obtain sharper results, we will now specialize the income tax policy to be history independent. That is, we assume that $s_{t}^{y}\left(h^{t-1}, i\right)$ is independent of $h^{t-1}$. We will say that an income tax policy $\tilde{\boldsymbol{s}}^{y}$ is more redistributive than an income tax policy $\boldsymbol{s}^{y}$ if it imposes a lower minimum tax burden than an alternative tax policy,

$$
\min _{i \in \mathcal{N}} \tilde{s}_{t}^{y}(i) \leq \min _{i \in \mathcal{N}} s_{t}^{y}(i) \quad \forall t \geq 0
$$

For example, suppose that the income tax is affine, $s_{t}^{y}(i)=-\eta_{0}+\eta_{1} y^{i}$. Then an increase in $\eta_{1}$ accompanied by a corresponding increase in $\eta_{0}$ generates a more redistributive policy. The, next proposition shows that income tax policies that are more redistributive cannot increase welfare. To that end, define $V^{*}\left(\boldsymbol{s}^{y}, \boldsymbol{s}^{c}\right)$ as the expected utility in a competitive equilibrium given the tax policy $\left(s^{y}, s^{c}\right)$ and values of autarky $V^{\mathrm{AUT}}\left(\boldsymbol{s}^{y}, \boldsymbol{s}^{c}\right)$.

Proposition 2. Suppose that income tax policies $\boldsymbol{s}^{y}$ and $\tilde{\boldsymbol{s}}^{y}$ are history independent, and $\tilde{\boldsymbol{s}}^{y}$ is more redistributive than $\boldsymbol{s}^{y}$. Then $V^{*}\left(\tilde{\boldsymbol{s}}^{y}, \boldsymbol{s}^{c}\right) \leq V^{*}\left(\boldsymbol{s}^{y}, \boldsymbol{s}^{c}\right)$.

Proof. Since $s^{y}$ and $\tilde{s}^{y}$ are history independent, the agents in autarky maximize utility by minimizing tax liabilities in every state of the world. Let $c^{\mathrm{AUT}}\left(\widetilde{\boldsymbol{s}}^{y}, s^{c}\right)$ be consumption in autarky under $\left(\tilde{s}^{y}, s^{c}\right)$ and $c^{\text {AUT }}\left(s^{y}, s^{c}\right)$ be consumption in autarky under $\left(s^{y}, s^{c}\right)$. They are given by

$$
c^{\mathrm{AUT}}\left(h^{t} ; \tilde{s}_{t}^{y}, s_{t}^{c}\right)=\max _{i \in \mathcal{N}} \frac{y^{h_{t}}-\tilde{s}_{t}^{y}(i)}{1+s_{t}^{c}} \geq \max _{i \in \mathcal{N}} \frac{y^{h_{t}}-s_{t}^{y}(i)}{1+s_{t}^{c}}=c^{\mathrm{AUT}}\left(h^{t} ; s_{t}^{y}, s_{t}^{c}\right),
$$

where the inequality follows from the assumption that $\tilde{s}^{y}$ is more redistributive than $s^{y}$. 
Thus, $\boldsymbol{V}^{\mathrm{AUT}}\left(\tilde{\mathbf{s}}^{y}, \boldsymbol{s}^{\mathcal{c}}\right) \geq \boldsymbol{V}^{\mathrm{AUT}}\left(\boldsymbol{s}^{y}, \boldsymbol{s}^{\mathcal{c}}\right)$, which in turn implies that $\hat{V}^{*} \geq V^{*}\left(\tilde{\mathbf{s}}^{y}, \boldsymbol{s}^{c}\right)$, where $\hat{V}^{*}$ is the expected utility in an equilibrium given $\left(\tilde{\boldsymbol{s}}^{y}, \boldsymbol{s}^{c}\right)$ and $\boldsymbol{V}^{\mathrm{AUT}}\left(\boldsymbol{s}^{y}, \boldsymbol{s}^{c}\right)$. Finally, it follows from Proposition 1 that $\hat{V}^{*}=V^{*}\left(\boldsymbol{s}^{y}, \boldsymbol{s}^{c}\right)$. Combining, $V^{*}\left(\boldsymbol{s}^{y}, \boldsymbol{s}^{c}\right) \geq V^{*}\left(\widetilde{s}^{y}, \boldsymbol{s}^{c}\right)$.

The result is an implication of a more general principle: whenever a change in the income taxes tightens the limited enforcement constraint, it will decrease welfare, because the direct effects are zero by Proposition 1. By the same token, if a change in income taxes neither increases nor decreases the minimum tax liability, it will have no effect on welfare. This result is similar to that obtained by Krueger and Perri (2011) where a more progressive income tax increases the value of autarky, which in turn reduces the extent of private risk sharing. However, Proposition 1 implies that the results in a private information environment differ markedly from the results in Krueger and Perri (2011) in one aspect: Income taxes affect the value of autarky only through the value of the minimum tax liability, while in Krueger and Perri (2011), all the other aspects of a history independent income tax matter as well.

In contrast to an income tax, a consumption tax matters in two different ways. Like the income tax it affects the value of autarky, but it also directly affects the incentive constraint. As seen from the right-hand side of the incentive constraint (3), any hidden earnings are taxed by a consumption tax before being consumed. When an agent claims to have a low endowment but in fact has a high endowment, the consumption tax ensures that the agent only is only able to enjoy a fraction of the difference between the low and the high endowment. In this sense, the consumption tax can bypass the information friction. This reduces the gains from misreporting income. ${ }^{5}$ We will return to the analysis of the consumption tax in section 5.

\footnotetext{
${ }^{5}$ In the limiting case of an infinite consumption tax the gains from misreporting income would be zero.
} 


\section{Recursive Formulation with Two Shock Values}

For computational purposes it is essential to provide a recursive representation of the optimal insurance contract. In order to provide such a representation, we begin by simplifying the government policies by insisting that both the consumption tax rate $s^{c}$ and the income tax are history and time independent. Given Proposition 2, we can confine our attention to a constant lump-sum income tax (or, more plausibly, transfer) $s^{y}$. Likewise, we assume that the intertemporal price $q$ is constant over time. We also restrict our attention to two shock values $y^{1}<y^{2}$ and write $\delta=(1+$ $\left.s^{c}\right)^{-1}\left(y^{2}-y^{1}\right)$. We assume that the stochastic process is persistent: the probability of getting a low shock is higher for a previously low type:

Assumption $2 \pi_{11} \geq \pi_{21}$.

Define an allocation rule by $(u, w)=\left\{u_{1}, u_{2}, w_{1}^{1}, w_{1}^{2}, w_{2}^{1}, w_{2}^{2}\right\}$, where $u_{i}$ is the current utility of an $i$-type agent who truthfully reports her shock, ${ }^{6}$ and $w_{j}^{i}$ is the continuation utility of type $i$ who reports to be of type $j$. The temporary incentive constraints require that a truthfully reporting agent's type is utility maximizing:

$$
\begin{aligned}
& u_{2}+\beta w_{2}^{2} \geq \psi\left(u_{1}, \delta\right)+\beta w_{1}^{2} \\
& u_{1}+\beta w_{1}^{1} \geq \psi\left(u_{2},-\delta\right)+\beta w_{2}^{1} .
\end{aligned}
$$

We also require that choosing autarky at the end of the current period cannot be optimal either for the truthtelling agents, or for the agents misreporting their types:

$$
\begin{array}{ll}
w_{j}^{1} \geq V_{1}^{\mathrm{AUT}} & j=1,2 \\
w_{j}^{2} \geq V_{2}^{\mathrm{AUT}} & j=1,2,
\end{array}
$$

\footnotetext{
${ }^{6}$ For each allocation rule the associated transfer rule defined via $\tau_{i}=\left(1-s^{c}\right)^{-1}\left(U^{-1}\left(u_{i}\right)-y^{i}-\right.$ $\left.s^{y}\right)$. Given a transfer rule, the transfer function $\tau$ can be defined recursively. We will also simplify notation by keeping the dependence on $s^{y}$ and $s^{c}$ implicit from now on.
} 
where the value of autarky (5) is now

$$
V_{i}^{\mathrm{AUT}}=\left[U\left(\frac{y^{1}-s^{y}}{1+s^{c}}\right)+\beta V_{1}^{\mathrm{AUT}}\right] \pi_{i 1}+\left[U\left(\frac{y^{2}-s^{y}}{1+s^{c}}\right)+\beta V_{2}^{\mathrm{AUT}}\right] \pi_{i 2} .
$$

In each period, an insurance provider is restricted to deliver a lifetime utility $v_{1}$ to a previously low type, and $v_{2}$ to a previously high type. The pair $\left(v_{1}, v_{2}\right)$ is an element of a state space $\mathcal{V} \subseteq \mathbb{R}^{2}$, which we characterize below. The promise keeping constraints are:

$$
v_{i}=\left(u_{1}+\beta w_{1}^{1}\right) \pi_{i 1}+\left(u_{2}+\beta w_{2}^{2}\right) \pi_{i 2}, \quad i=1,2 .
$$

Finally, we require that the continuation utilities are again elements of the state space:

$$
\left(w_{i}^{1}, w_{i}^{2}\right) \in \mathcal{V} \quad i=1,2
$$

An allocation rule $(u, w)$ is said to implement a promised utility pair $\left(v_{1}, v_{2}\right)$ if it satisfies the constraints (8), (11), (9) and (12).

\subsection{The Set of Implementable Utilities}

We now define and characterize the state space, or the set of implementable utilities $\mathcal{V} \subseteq \mathbb{R}^{2}$. It is defined as the set of all promised utility pairs $v=\left(v_{1}, v_{2}\right)$ such that there exists some allocation rule that implements it, i.e. is incentive compatible, satisfies the promise-keeping constraints, the limited enforcement constraints, and such that its continuation utilities are again in the set $\mathcal{V}$ :

$$
\mathcal{V}=\left\{\left(v_{1}, v_{2}\right) \in \mathbb{R}^{2} \mid \exists(u, w) \text { s.t. (8), (11), (9) and (12) holds }\right\}
$$

The following Proposition shows that $\mathcal{V}_{i}$ is convex whenever the utility exhibits decreasing relative risk aversion, and the incentive constraint on the low type is not 
binding.

Proposition 3. If Assumption 1 holds and the incentive constraint (8b) is slack, then $\mathcal{V}$ is convex.

Proof. See Appendix A.

A useful way of characterizing the state space $\mathcal{V}$ is to characterize its lower and upper bounds. Define these bounds by minimizing and maximizing the utility of the high type by keeping the utility of the low type fixed:

$$
\begin{aligned}
& \underline{V}\left(v_{1}\right)=\min \left\{v_{2} \mid\left(v_{1}, v_{2}\right) \in \mathcal{V}\right\}, \\
& \bar{V}\left(v_{1}\right)=\max \left\{v_{2} \mid\left(v_{1}, v_{2}\right) \in \mathcal{V}\right\} .
\end{aligned}
$$

The next proposition shows that the set $\mathcal{V}$ is a subset of a pointed cone defined by a 45 degree line and a line with a slope $\pi_{21} / \pi_{11}<1$ :

Proposition 4. The upper and lower bounds of the set $\mathcal{V}$ satisfy

$$
\begin{aligned}
& \underline{V}\left(v_{1}\right) \geq v_{1} \\
& \bar{V}\left(v_{1}\right) \leq \frac{\pi_{21}}{\pi_{11}} v_{1},
\end{aligned}
$$

In addition, $\underline{V}\left(V_{1}^{\mathrm{AUT}}\right)=V_{2}^{\mathrm{AUT}}$.

Proof. See Appendix A.

The red set in Figure 1 is a typical set of feasible utilities $\mathcal{V}$. The details of the proof of Proposition 4 are relegated to Appendix A, and we only sketch an outline of the proof here. The upper bound can be obtained by ignoring the incentive compatibility constraint and solving for the resulting upper bound. The solution in the absence of the incentive constraints is to assign a lifetime utility $u_{i}+\beta w_{i}$ as low as possible to a state where the deviator is the least likely to be relative to the truthteller, and to assign zero lifetime utility (bliss) to the other state. Given Assumption 2, the unlikeliest state is the low state $i=1$ and one can easily verify that the upper contour then takes the form given in Proposition 4. The intuition behind the lower bound is that the deviator always has the option of pretending to be of the low type. If he does so, he consumes all the transfers of the lower 
type. However, since his past endowment is higher and Assumption 2 holds, he can secure himself a lifetime utility greater than the utility of the truthteller $v_{1}$. Note also that if the shocks are i.i.d., $\pi_{21} / \pi_{11}=1$ and the cone shrinks to a line with a slope of 1 . That is, the deviator's utility is then always the same as the truthteller's utility. ${ }^{7}$

Proposition 4 shows that the value of the lower bound is the autarkic value of the deviator $V_{2}^{\text {AUT }}$. Remarkably, the result holds even given that the constraint (9b) is not explicitly imposed. Since the lower bound is increasing, it follows that once the constraint (9a) is imposed, it is never optimal to deviate jointly by misreporting in the current period and then choosing autarky and so constraint (9b) can be ignored:

Proposition 5. The constraint (9b) is slack.

Proof. Proposition 4 shows that $\underline{V}\left(V_{1}^{\text {AUT }}\right)=V_{2}^{\text {AUT }}(s)$ without the constraint $(9 \mathrm{~b})$ being imposed. Since $\underline{V}\left(v_{1}\right)$ increases in $v_{1}$, if $\left(w_{i}^{1}, w_{i}^{2}\right) \in \mathcal{V}$ then $w_{i}^{2} \geq \underline{V}\left(w_{i}^{1}\right) \geq V_{2}^{\text {AUT }}$, whenever $w_{i}^{1} \geq V_{1}^{\mathrm{AUT}}$.

If the value of autarky is minus infinity, then the set of implementable utilities simplifies further. The lower bound is now a straight line, as illustrated by the black cone in Figure 1:

Proposition 6. If $V_{1}^{\mathrm{AUT}}=-\infty$ then $\underline{V}(v)=v$.

Proof. Consider an allocation that assigns $u_{1}=u_{2}=0$ and $w_{i}^{i}=\frac{v}{\beta}$. This allocation is trivially incentive compatible since it is independent of the report. It also delivers $v_{2}=v_{1}$. Since the value of autarky is minus infinity, inequalities (9) trivially hold. Hence $\underline{V}(v) \leq v$. Given that $\underline{V}(v) \geq v$ by Proposition 4, it follows that $\underline{V}(v)=v$.

Finally, the properties of the set of implementable utilities imply the following result that lifetime utilities conditional on the current shock are monotonically increasing in the current shock:

Proposition 7. If $(u, w)$ implements $\left(v_{1}, v_{2}\right) \in \mathcal{V}$ then $u_{2}+\beta w_{2}^{2}>u_{1}+\beta w_{1}^{1}$.

\footnotetext{
${ }^{7}$ This is the case analyzed by Thomas and Worrall (1990), whose state space is one-dimensional.
} 


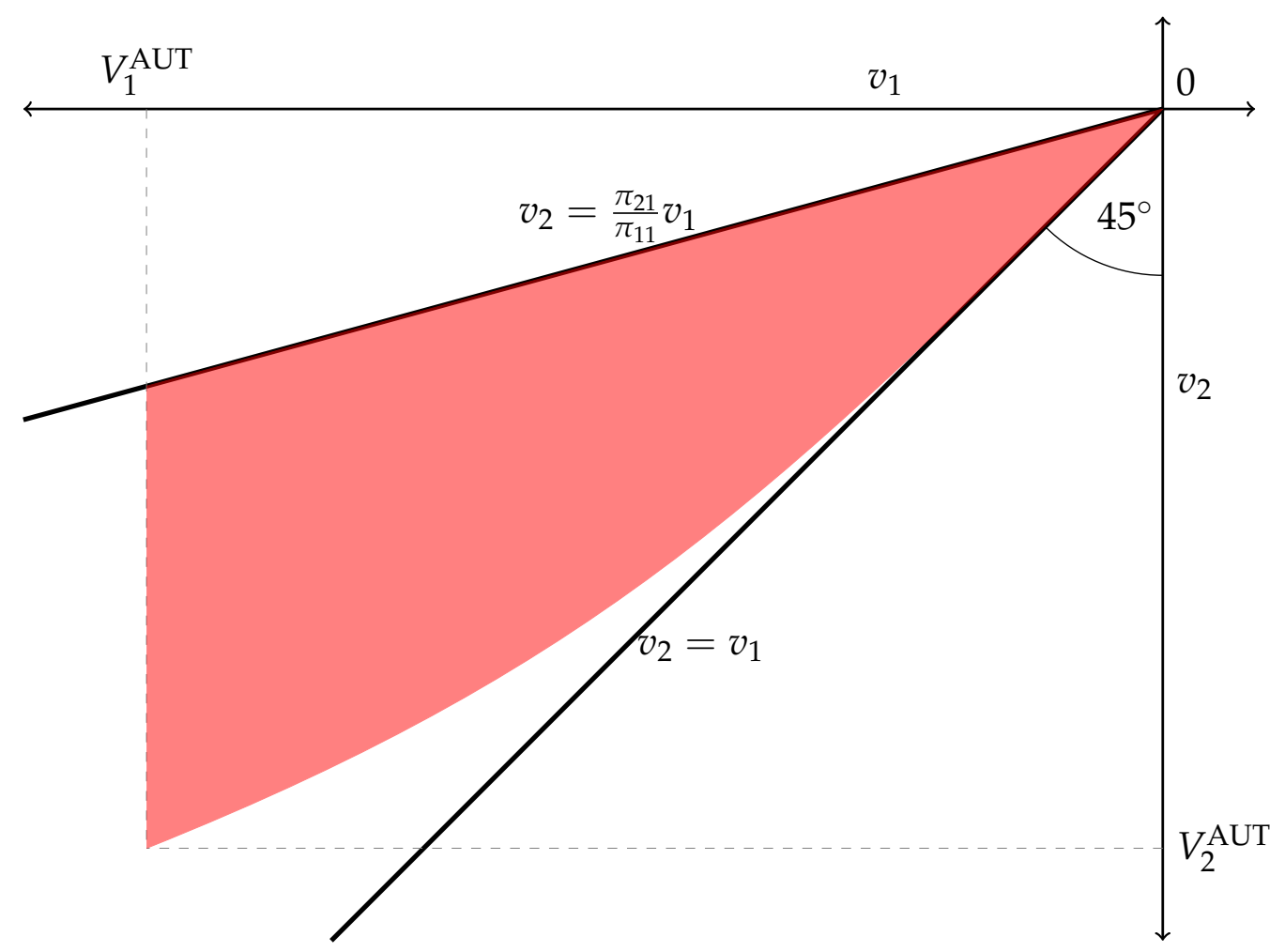

Figure 1: The Set of Feasible $\left(v_{1}, v_{2}\right)$ Pairs

Proof. The incentive constraint (8a) implies that

$$
u_{2}+\beta w_{2}^{2} \geq \psi\left(u_{1}, \delta\right)+\beta w_{1}^{2} \geq \psi\left(u_{1}, \delta\right)+\beta \underline{V}\left(w_{1}^{1}\right) \geq u_{1}+\beta w_{1}^{1}
$$

where the second inequality follows from the definition of $\underline{V}$, and the third one from Proposition (4) and the properties of $\psi$.

\subsection{A Separation Property}

We will now rearrange the incentive constraints (8) and the promise keeping constraints (11) to show that the problem exhibits the following separation property: Given $\left(v_{1}, v_{2}\right) \in \mathcal{V}$, one can solve for the allocation rule in the current low state independently of the allocation rule in the current high state. The profit maximization problem then separates into two 
independent ex-post subproblems. In addition, we will show that the optimal allocation rule is independent of the previous state. Both ex-post subproblems have a very symmetric structure, and to highlight it, define $\hat{u}_{2}=\psi\left(u_{2},-\delta\right)$ to be the period utility of a deviator who receives a high shock, but reports a low shock. The promise keeping constraints (11) constitute a set of linear equations in $(u, w)$ and one can write them as

$$
\begin{aligned}
& \mu_{1}\left(v_{1}, v_{2}\right)=u_{1}+\beta w_{1}^{1} \\
& \mu_{2}\left(v_{1}, v_{2}\right)=\psi\left(\hat{u}_{2}, \delta\right)+\beta w_{2}^{2},
\end{aligned}
$$

where the functions $\mu$ are linear in $v=\left(v_{1}, v_{2}\right)$, and are given by $\mu(v)=\pi^{-1} v$, with $\pi^{-1}$ being the inverse of the transition matrix. One can in turn rewrite the incentive constraints (8) as follows:

$$
\begin{aligned}
& \mu_{2}\left(v_{1}, v_{2}\right) \geq \psi\left(u_{1}, \delta\right)+\beta w_{1}^{2} \\
& \mu_{1}\left(v_{1}, v_{2}\right) \geq \hat{u}_{2}+\beta w_{2}^{1} .
\end{aligned}
$$

Note that the constraints (13a) and (14a), as well as the constraints (9) and (12) contain only the allocation rule for the current low state $\left(u_{1}, w_{1}^{1}, w_{1}^{2}\right)$. Similarly, the constraints $(13 \mathrm{~b})$, (14b), (9) and (12) contain only the allocation rule for the current high state $\left(u_{2}, w_{2}^{1}, w_{2}^{2}\right)$. The objective function of the insurance provider is additively separable in the allocation rule for the low and high state. Thus, one can choose the allocation rule for each state independently of each other.

Furthermore, the fact that the allocations can be chosen conditionally on the current state implies that the previous state is no longer relevant. Hence the maximization problem can be written independently of the previous state $i_{-}$. Denote the profit function conditional on the current state $i$ by $Q_{i}\left(v_{1}, v_{2}\right)$. It satisfies the following Bellman equation:

$$
\begin{aligned}
& Q_{1}\left(v_{1}, v_{2}\right)=\max _{u_{1}, w_{1}^{1}, w_{1}^{2}}\left\{y^{1}-U^{-1}\left(u_{1}\right)+q P_{1}\left(w_{1}^{1}, w_{1}^{2}\right)\right\} \text { s.t. (9), (12), (13a), (14a) } \\
& Q_{2}\left(v_{1}, v_{2}\right)=\max _{\hat{u}_{2}, w_{1}^{1}, w_{2}^{2}}\left\{y^{2}-U^{-1}\left(\hat{u}_{2}\right)+q P_{2}\left(w_{2}^{1}, w_{2}^{2}\right)\right\} \text { s.t. (9), (12), (13b), (14b), }
\end{aligned}
$$


where $P_{i}\left(v_{1}, v_{2}\right)$ is the expected profit function conditional on the current shock $i$ :

$$
P_{i}\left(v_{1}, v_{2}\right)=\pi_{i 1} Q_{1}\left(v_{1}, v_{2}\right)+\pi_{i 2} Q_{2}\left(v_{1}, v_{2}\right)
$$

Each of the two subproblems are in effect ex-post problems, once the current shock has been realized. Moreover, the subproblems are symmetric: the two constraints (13a), (14a) have the same functional form as (13b), (14b), but differ with respect to whether they hold as weak inequality, or as equality.

The fact that the optimal allocation rule is independent of the previous shock may appear puzzling. In an alternative recursive formulation in Fernandes and Phelan (2000), the optimal allocation rule exhibits dependency on the previous shock. The key "trick" in our formulation is that we dispense with the notion of a promised utility of the truthteller and a promised utility of a deviator, and simply keep track of promised utilities for the low and high type. Although this may seem to be merely a notational change at first sight, it has one important and nontrivial consequence: the low and high types are independent of the previous period shock, while the identity of a truthteller and a deviator depends on it: If a previous shock was high then the deviator is of low type and vice versa. More formally, let $\tilde{u}_{i}\left(v, \hat{v}, i_{-}\right)$be the current utility as a function of a truthteller's utility $v$ and deviator's utility $\hat{v}$, as in Fernandes and Phelan (2000). Then the current utility function is symmetric in the sense that $\tilde{u}_{i}(v, \hat{v}, 1)=u_{i}(v, \hat{v})$ and $\tilde{u}_{i}(v, \hat{v}, 2)=u_{i}(\hat{v}, v)$, for $i=1,2$. An analogous argument applies for the continuation utilities as well, and so for the whole allocation rule.

\subsection{General Equilibrium}

We now define, for the purpose of approaching the data, a stationary competitive equilibrium. Relative to Section 2 we modify it to allow for aggregate capital accumulation and impose stationarity. We assume that output is produced by competitive firms using an aggregate production function $Y=A K^{\theta} N^{1-\theta}$, where $K$ is the aggregate capital stock, $N=\mathbb{E}[y]=1$ is aggregate labor supply, and $A$ is total factor productivity. The capital stock depreciates at rate $\delta_{K}$. Capital is owned by the insurance providers. This means that, in autarky, consumers receive no capital income. Wages, however, including those received 
in autarky, are determined by the size of the aggregate capital stock. ${ }^{8}$

A stationary competitive equilibrium is characterized by an intertemporal price of consumption $q$, wage $w$ and a distribution of the promised utilities and current shock $\left(v_{1}, v_{2}, i\right)$ such that (i) the distribution is stationary, (ii) the allocation rule $(u, w)$ maximizes the profits of the financial intermediary taking prices $(q, w)$ and autarky values as given, (iii) firms maximize profits, i.e.

$$
\begin{aligned}
q^{-1}+\delta-1 & =A \theta K^{\theta-1} \\
w & =A(1-\theta) K^{\theta},
\end{aligned}
$$

(iv) the resource constraint holds,

$$
C+\delta_{K} K=A K^{\theta}
$$

where $C=\mathbb{E}[c]$ is aggregate consumption, and (v) the government budget constraint balances,

$$
s^{c} C+s^{y}=0 .
$$

\section{Risk Sharing Properties Compared to US Data and Other Models}

In this section, we compare the quantitative implications of our theory to US micro-data, and to the implications of two other popular models of consumption risk sharing: BewleyAiyagari (SI) type models where the agents can only self-insure through borrowing and saving $^{9}$ and Krueger-Perri (LE) type models where the insurance contracts are limited only by the enforcement constraints. ${ }^{10}$

\footnotetext{
${ }^{8}$ This externality means that there is no reason to believe that the competitive equilibrium is constrained efficient. We owe this insight to Abraham and Cárceles-Poveda (2009).

${ }^{9}$ See Bewley (1977), Aiyagari (1994) and Huggett (1993).

${ }^{10}$ See Krueger and Perri (2004), Krueger and Perri (2006), and Krueger and Uhlig (2006).
} 


\subsection{Earnings and Consumption in US Data}

The data sources used for the estimation of the income process and of the key moments of consumption risk-sharing are, respectively, the Panel Study of Income Dynamics (PSID) and the Consumer Expenditure Survey (CEX), the main sources of income and consumption data for the United States. Our variable definitions and sample selection closely follow Heathcote et al. (2010).

Earnings. The appropriate measure of earnings for our model are household earnings net of taxes and government transfers, but excluding private transfers. Our consumption measure is expenditure on non-durables, and the frequency of measurement is annual. For earnings, we use a PSID sample from 1967 to 2002 that is selected according to the same principles as that of Sample C in Heathcote et al. (2010). This means that we exclude observations with values of earnings that are zero or negative and also that we exclude observations with positive labour earnings but zero hours worked or where earnings and hours are such as to imply an hourly wage less than half the minimum wage for the relevant year. In addition, extreme values were deleted in order to focus on what might be called ordinary households. Specifically, we delete, for each year, the bottom and top 2.5 percentiles.

For both consumption and earnings we identify the idiosyncratic component as the residuals from a first-stage regression on a set of observable household characteristics $Z_{i, t}$ known by household $i$ at time $t$. Specifically, we consider $Z_{i, t}$ to comprise dummies describing whether the household is a married couple, a single man or a single woman and whether the adult members of the household have more than 12 years of education, time dummies and a polynomial in the age of the head of household. The covariates account for about 40 percent of the total variance of earnings in our PSID sample. A histogram of the residuals from the first-stage regression can be seen in Figure 2.

Our approach to estimating the earnings process is designed to capture the key statistical properties in micro data and to produce an earnings process that is consistent with our theoretical framework. We obtain the earnings process for each household $i$ by decomposing the residual idiosyncratic component $\ln y_{i, t}$ of log earnings (whose unconditional mean is zero by construction) into three components as follows

$$
\ln y_{i, t}=\alpha_{i}+z_{i, t}+x_{i, t}
$$




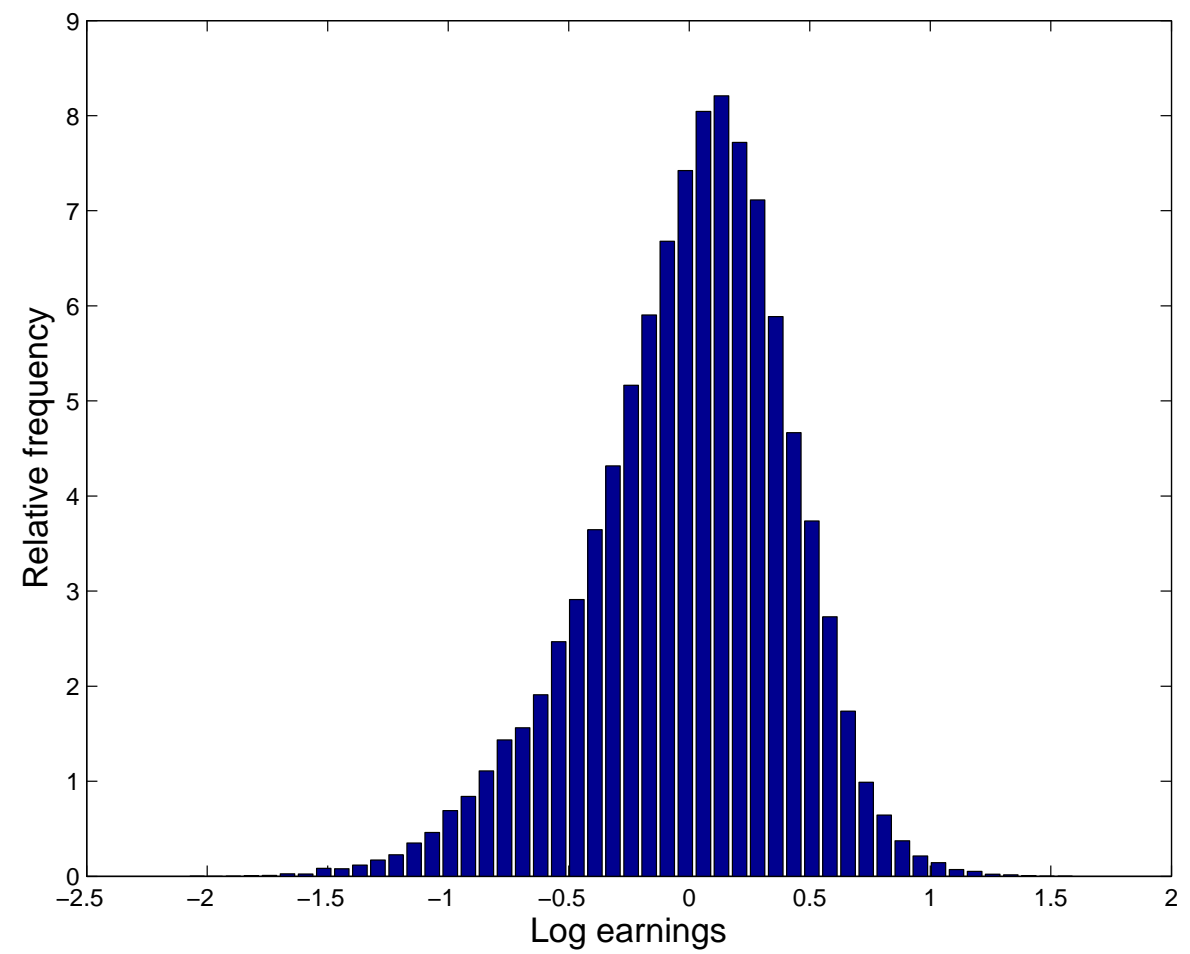

(a) Histogram for residual log earnings in the PSID 1967-2002

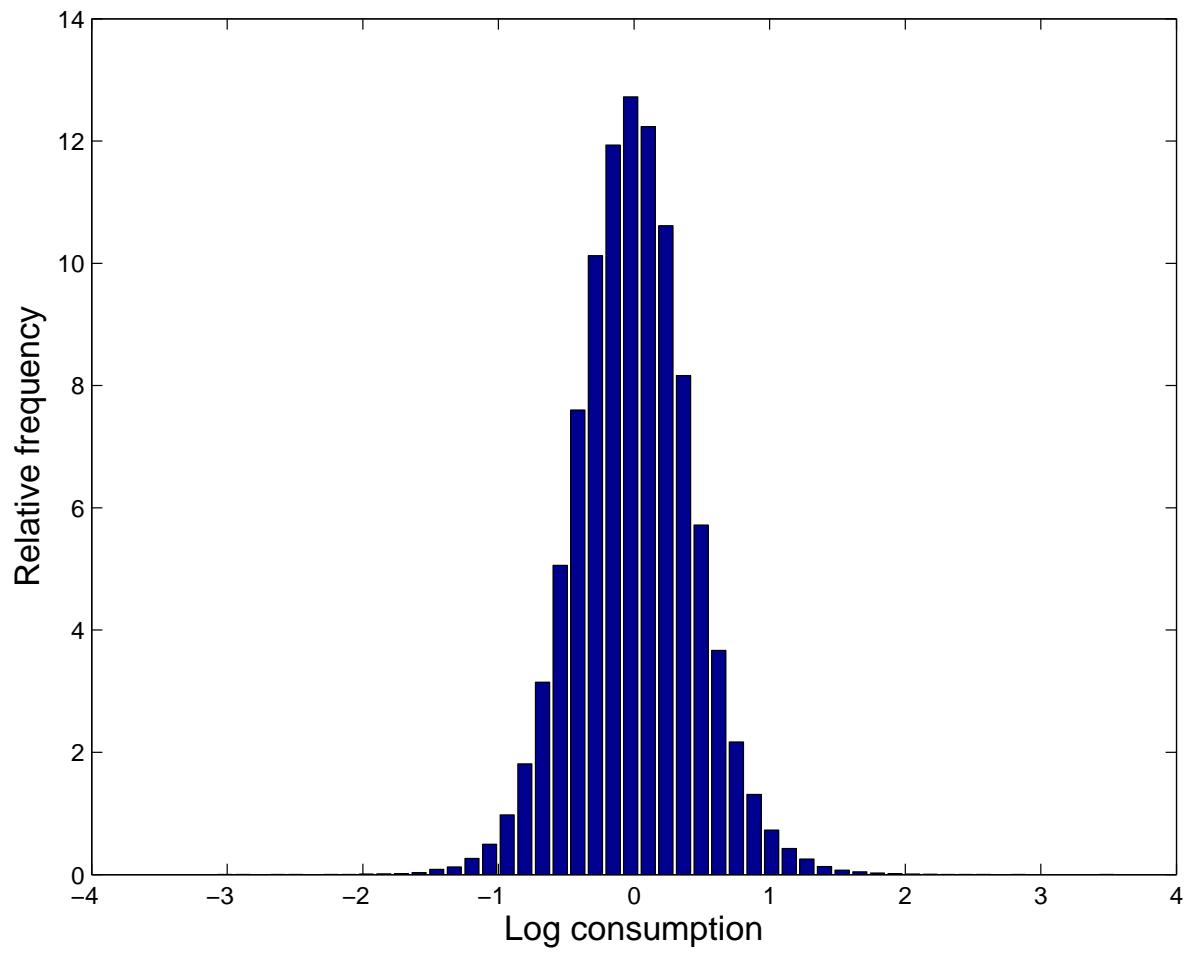

(b) Histogram for residual log consumption in the CEX 1980-2003

Figure 2: The empirical distribution of earnings and consumption residuals 
where $\alpha_{i}$ is the permanent (unchanging) component, $z_{i, t}$ is the persistent, and $x_{i, t}$ is the transitory (i.i.d.) component. We decide to treat the purely transitory component as measurement error and the permanent component as inherently uninsurable. Therefore the relevant component for our risk sharing analysis is the persistent component. It satisfies

$$
z_{i, t-1}=\rho z_{i, t-1}+\varepsilon_{i, t}
$$

where $\varepsilon_{i, t}$ is an i.i.d. shock. ${ }^{11}$ The parameters that characterize the income process are the variances of the shocks $\sigma_{\varepsilon}^{2}, \sigma_{x}^{2}$ and $\sigma_{\alpha}^{2}$, the autocorrelation of the persistent shock $\rho$ and the third central moments of $\alpha_{i}, x_{i, t}$ and $\varepsilon_{i, t}$. Appendix B describes in detail how we estimate these moments from PSID data using a GMM procedure.

The first panel of Table 1 reports the values of the standard deviation, skewness and autocorrelation of the persistent earnings component $z$. Interestingly, the persistent component of earnings has a significant left (negative) skew. The implied variance of persistent shocks $\varepsilon$ is, as expected, very similar to that reported in Heathcote et al. (2010) who, however, assume these shocks to have permanent effects, and allow their variance to change over time. $^{12}$

Table 1: Estimated moments

\begin{tabular}{cc}
\hline Persistent earnings component \\
$\sigma_{z}$ & 0.329 \\
skew $z$ & -0.576 \\
$\rho$ & 0.925 \\
\hline
\end{tabular}

Consumption. For our CEX sample that comprises the years 1980 to 2006 we perform a very similar sample selection as in the PSID. ${ }^{13}$ In CEX data (reported in Table 2) consumption

\footnotetext{
${ }^{11}$ An alternative approach is taken by Guvenen (2007) who posits heterogeneity in the growth rate of earnings. Guvenen justifies it by referring to the implied behavior of consumption. While we find Guvenen's argument interesting, it is done in the context of a financial market with riskless one-period bonds only and cannot be directly applied to our PILE model. We regard our work as complementary to Guvenen's.

${ }^{12} \mathrm{~A}$ defence of the approach used here can be found in Klein and Telyukova (2013). The only difference between the approach used here and theirs is that we estimate skewness parameters in addition to parameters governing second moments. For more on the issues involved in estimating earnings processes, see Manovskii et al. (2014).

${ }^{13}$ Specifically, we drop households where neither head nor spouse are between 25 and 60 years of
} 
residuals have a standard deviation that is only about $17 \%$ smaller than that of the CEX earnings measure. A striking feature of the data is that the cross-sectional distribution of (log) consumption is much more symmetric than that of earnings; see Figure 2. In fact, (log, residual) earnings are somewhat skewed to the left, with a skewness coefficient (the third central moment divided by the cube of the standard deviation) of about $-0.531^{14}$, similar to that for the persistent component reported in Table 1. The fact that log consumption is distributed more symmetrically than earnings was first noted by Battistin et al. (2009) for the United Kingdom and is also documented for Canada in Brzozowski et al. (2010).

A common measure of the degree of risk sharing is the regression coefficient of (residual) consumption changes on (residual) earnings changes. As pointed out in Gervais and Klein (2010), the structure of the CEX presents some difficulties in estimating this statistical moment in U.S. data, due to the fact that consumption and income are not measured for the same time periods.) Using their approach to estimate this coefficient in a consistent manner on our sample yields a value of $0.22 .{ }^{15}$ Using a more straightforward, but invalid, OLS approach, the number is about 0.079 . This is evidence of significant risk sharing: consumption does not respond very strongly to earnings changes.

\subsection{Alternative Models}

We now compare the risk sharing properties that arise in the benchmark equilibrium of our PILE model to those from alternative models. First, we investigate a version of the Krueger-Perri economy where agents can write state-contingent contracts but the lack of contract enforcement implies participation constraints that endogenously limit risk sharing. We call this model the LE ("limited enforcement") model. Second, we investigate a version of the Bewley-Aiyagari economy where agents can smooth consumption only by saving and borrowing using a non-contingent riskless asset. We investigate two versions of the Bewley-

age, or where either head or spouse receives a wage smaller than half the minimum, and where the head works less than 260 hours per year. We exclude income outliers as in the PSID sample, and households whose responses we deem unreliable because their reported race changes, or because they report becoming less educated or age too fast or become younger over time.

${ }^{14}$ Source: PSID.

${ }^{15}$ Notice that (i) the Gervais and Klein (2010) approach used here delivers a consistent estimate of the regression coefficient of quarterly consumption changes on quarterly earnings changes and that (ii) the value that Gervais and Klein (2010) themselves report for this coefficient, based on a broader sample than that used here, is 0.15 . 
Aiyagari economy: one where the agents face a natural borrowing limit, which we call the SIN ("self-insurance with natural borrowing limit") economy and one where the borrowing limit is the maximum borrowing limit that prevents the agents from defaulting tomorrow as in Zhang (1997), which we call the SILE ("self-insurance with limited enforcement") model.

In formulating the alternative models, we continue to assume that the government policy $s$ consists of a time invariant lump-sum income tax (transfer) $s^{y}$, and a consumption tax rate $s^{c}$. The government budget constraint (17) thus continues to hold. We also keep the preferences (1) and the aggregate resource constraint (16) unchanged. Since the recursive formulations are easier in both Krueger-Perri and Bewley-Aiyagari, we write the models for an arbitrary number of shocks $N$.

Krueger-Perri LE model. To highlight the effect of limited information on the equilibrium allocation in the PILE model, we contrast it to an environment where intermediaries offer insurance contracts under a limited enforcement constraint, but with full information about agents' income histories. Specifically, consider a version of the benchmark environment in which competitive insurance providers maximize expected profits as defined in Equation (2) by investing in capital and offering insurance contracts to the agents subject to the limited enforcement constraint. For comparability with previous contributions we also adopt the standard timing assumption in LE models, that agents can choose the outside option before any transfers are made (while in our PILE model the agent can only choose to move to autarky after current-period transfers).

$$
V_{i}^{\mathrm{AUT}}=U\left(\frac{y^{i}-s^{y}}{1+s^{c}}\right)+\beta \sum_{j \in \mathcal{N}} V_{j}^{\mathrm{AUT}} \pi_{i j} .
$$

The insurance providers and the government have full information about income histories, and can disregard the incentive constraint (3).

A stationary competitive equilibrium of the LE environment is characterized by an interest rate $R=q^{-1}$, a wage $w$ and a distribution of promised utilities and the current shock $(v, i)$ such that (i) the distribution of is stationary, (ii) the allocation rule $(u, w)$ maximizes the profits of the financial intermediary taking prices $(q, w)$ and autarky values as given, (iii) firms maximize profits, i.e. (15) holds, (iv) the resource constraint (16) holds, and (v) government budget constraint (17) holds. 
Bewley-Aiyagari SIN and SILE models. Agents maximise utility (2) by choosing noncontingent assets $b_{t}$ every period subject to the following budget constraint

$$
\left(1+s^{c}\right) c_{i}+b_{i}^{\prime}=y^{i}-s^{y}+R b
$$

taking as given the interest rate $R$ and a borrowing limit $\underline{b}$ such that $b_{i}^{\prime} \geq \underline{b}$. We study two versions of the economy distinguished by the value of $\underline{b}$. First, we look at the SIN ("selfinsurance with natural borrowing limit"), where $\underline{b}$ equals the natural borrowing limit $\underline{b}^{\mathrm{N}}$, given by

$$
\underline{b}^{\mathrm{N}}=-\frac{y^{1}}{R-1}
$$

Second, we look at an economy where $\underline{b}$ equals the maximum level of borrowing today $\underline{b}^{\mathrm{LE}}$ such that agents do not prefer to default in any income state tomorrow (Zhang (1997)):

$$
\underline{b}^{\mathrm{LE}}=\min \left\{b \mid V_{i}(b) \geq V_{i}^{\mathrm{AUT}} \quad \forall i \in \mathcal{N}\right\}
$$

where $V_{i}(b)$ is the expected lifetime utility of an agent with assets $b$ and income $y_{i}$ given tax policy $s$ and $V_{i}^{\mathrm{AUT}}$ is the value of autarky, as defined in (18). We call this model the SILE ("self-insurance with limited enforcement") model. Note that as in our PILE model, we assume that default implies complete debt-forgiveness but excludes agents from any saving or borrowing in the future. Thus agents that default consume their after-tax income forever.

A stationary competitive equilibrium in the SIN economy is characterized by a borrowing limit $\underline{b}^{\mathrm{N}}$, an interest rate $R=q^{-1}$, a wage $w$ and a distribution of assets and the current shock $(b, i)$ such that (i) the distribution is stationary, (ii) households maximise their utility (2) taking interest rates and wages $(q, w)$ as well as borrowing limits $\underline{b}^{\mathrm{N}}$ as given, (iii) firms maximize profits, i.e. (15) holds, (iv) the resource constraint (16) holds, and (v) government budget constraint (17) holds. A stationary competitive equilibrium in the SILE economy is defined analogously, with $\underline{b}^{\mathrm{LE}}$ replacing $\underline{b}^{\mathrm{N}}$. 


\subsection{Calibration and Benchmark Results}

We calibrate the support and transition probabilities of the earnings process to yield a process with the same standard deviation, skewness and autocorrelation as the estimated process for the persistent component of earnings $z_{i, t}$ (see Table 1). The average earnings are normalized to one, leaving two earnings levels and two transition probabilities to be chosen in order to match four targets. The procedure yields $y^{1}=0.614, y^{2}=1.218, \pi_{11}=0.952$ and $\pi_{22}=0.973$.

In the benchmark economy we set both tax rates $s^{y}$ and $s^{c}$ to 0 . Agents' period utility function is of the constant relative risk aversion form

$$
U(c)=\frac{c^{1-\sigma}}{1-\sigma^{\prime}}
$$

where we choose $\sigma=2$. In our benchmark annual calibration, we choose an interest rate $R=q^{-1}$ equal to 1.04. We assume that firms operate a Cobb-Douglas technology with capital share parameter $\theta=0.36$ and choose a value for the depreciation rate $\delta$ consistent with a stationary capital-output ratio equal to 3 , yielding $\delta_{K}=0.08$. We choose a total factor productivity parameter $A$ to normalize wages $w$ to 1 by setting $A(1-\theta) K^{\theta}=1$. We then calibrate the benchmark value for the discount factor $\beta$ to be such that the resource constraint (16) holds. Our benchmark calibration delivers $\beta=0.958$.

We choose parameters for the LE, SILE and SIN economies in two different ways. In the first, general equilibrium exercise, we keep the benchmark earnings process, the technology parameters $A$ and $\theta$, as well as the coefficient of relative risk aversion $\sigma$ unchanged. We also keep the interest rate $R=1.04$, and look for the discount factor to clear the resource constraint (16). That is, like in the benchmark calibration of the PILE economy, we are looking for a stationary general equilibrium by choosing discount factors that yield an interest rate of $R=1.04$ in the three alternative models. This exercise yields $\beta=0.957$ in the SIN economy and $\beta=0.953$ in the SILE economy. In the LE economy, as will be discussed below, this exercise yields full insurance implying $\beta=R^{-1}$.

In the second, partial equilibrium exercise, we keep the value of $\beta$ from the PILE economy, maintain the interest rate fixed at $R=1.04$ and solve for the optimal allocations without requiring the resource constraint (16) to clear. The reason we also look at this second set 
of partial equilibrium moments is twofold. First, the relative values of interest rate and discount factor have been identified as a key determinant of the degree of risk sharing. Comparing the key features of the models also at identical values of $\beta R$ makes the analysis, in our view, more robust to any misspecification of the asset supply that could affect our calibration of $\beta$ (e.g. due to the abstraction from any open economy considerations). Second, the LE model predicts perfect insurance in a general equilibrium, implying $\beta R=1$. Looking at a partial equilibrium with $\beta R<1$ allows us to also discuss the key moments of the income and consumption distribution in the LE model.

Risk sharing in the PILE economy. Table 2 shows three empirical moments of consumption risk sharing: the standard deviation of log consumption relative to disposable income $\sigma_{\ln c} / \sigma_{\ln y}$, the regression coefficient of percentage consumption changes on percentage earnings changes $\gamma$ as derived in Gervais and Klein (2010) and the skewness of log consumption skew $\ln c$, and compares them with their counterparts in the four models. The third row of Table 2 reports the results for the PILE model. The standard deviation of log consumption is 0.27 , about 81 percent the standard deviation of earnings. The regression coefficient of consumption changes on income changes is 0.22 , close to the (quarterly) coefficient in CEX data. Meanwhile, the skewness of log consumption in the PILE model is -0.940 , which is somewhat greater in magnitude than the skewness of log earnings. The upper panel of Figure 3 presents a histogram of the stationary equilibrium distribution of $\log$ consumption. The most striking feature is its bimodal character: while higher consumption values are distributed in a bell-like pattern around a value of about 0.2 , there is bunching in the left tail at the lower bound where participation-constraints of low income individuals are binding. To understand the shape of the stationary distribution, it is useful to consider the dynamic features of consumption and earnings. Specifically, consumption drifts up when earnings are high, and drifts down when they are low. The downward drift, however, is bounded by the lower earnings level where the participation constraint binds: were consumption to drop below this level, the agent would walk away. The upwardand downward drift, together with the approximately constant probability of experiencing a change in income status are behind the bell-like shape of the right-hand side of the stationary consumption distribution. The binding lower limit, at which low-income individuals remain until they experience a high income shock, explains the bunching at the 
Table 2: Aggregate Moments

\begin{tabular}{cccc}
\hline & $\sigma_{\ln c} / \sigma_{\ln y}$ & $\gamma$ & $\operatorname{skew} \ln c$ \\
\hline Data (CEX) & 0.832 & $0.225^{\dagger}$ & 0.0646 \\
& $(0.00401)$ & $(0.0341)$ & $(0.0177)$ \\
\hline \multicolumn{4}{l}{ General Equilibrium } \\
PILE & 0.813 & 0.220 & -0.940 \\
LE & $\mathrm{N} / \mathrm{A}$ & 0 & $\mathrm{~N} / \mathrm{A}$ \\
SIN & 1.385 & 0.361 & -1.823 \\
SILE & 0.873 & 0.406 & -0.904 \\
Partial Equilibrium & & \\
LE & 0.094 & 0.030 & -3.680 \\
SIN & 1.316 & 0.308 & -1.673 \\
SILE & 0.950 & 0.280 & -0.785 \\
\hline
\end{tabular}

$\sigma_{\ln c} / \sigma_{\ln y}$ is the standard deviation of $\log$ consumption relative to disposable income. The parameter $\gamma$ is the regression coefficient of percentage consumption changes on percentage earnings changes. skew $\ln c$ is skewness of $\log$ consumption.

${ }^{+}$Quarterly coefficient estimated using the method in Gervais and Klein (2010). The more standard, but misspecified, annual coefficient is 0.0793 , with a standard deviation of 0.00768 .

lower bound.

Risk sharing in the Krueger-Perri LE economy. The LE model is known to imply strong risk sharing in production economies with capital. This is because the returns from capital make the inside option of the insurance mechanism more attractive relative to the outside option of autarky, where agents only consume their labour income. For the calibration in Krueger and Perri (2006), with a more general income process including purely transitory shocks, this yields very strong but not perfect risk sharing, ${ }^{16}$ which helps to explain the small increase in consumption inequality in response to the observed increase in income inequality in the US since 1980. In our economy with two income shocks, the LE model actually predicts perfect risk sharing in a general equilibrium. Taken at face value, this implies a regression coefficient $\gamma=0$, as consumption is independent of income shocks. The remaining two moments in Table 2, however, are not defined, as the stationary distri-

\footnotetext{
${ }^{16}$ Using the income process that Krueger and Perri (2006) identify for the year 2003, their calibration yields a standard deviation of log consumption that is $20 \%$ that of incomes, a coefficient $\gamma$ of 0.007 , and a skewness of -1.3 .
} 


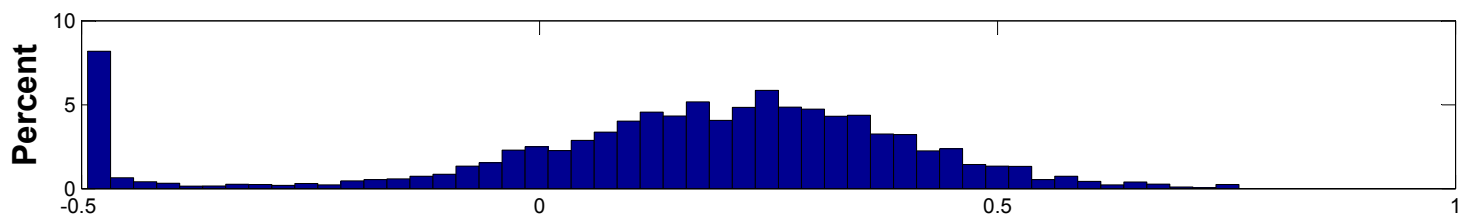

PILE

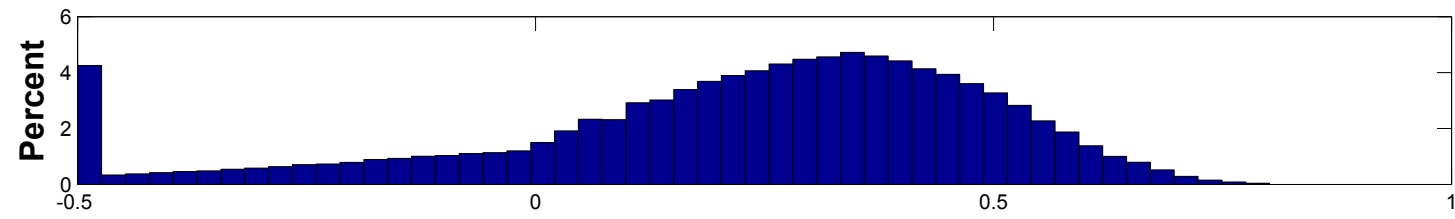

SILE
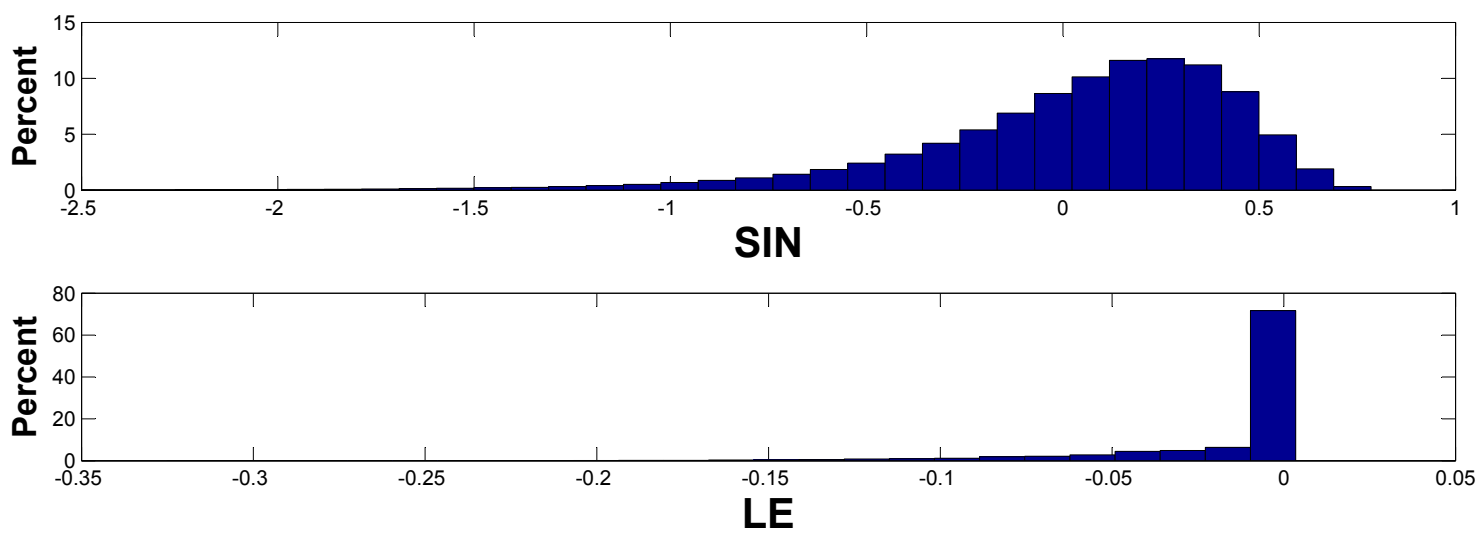

Histograms of the cross-sectional distribution of log consumption in the PILE, SILE, SIN and LE model in the partial equilibrium with common $\beta=0.957$ and $R=1.04$.

Figure 3: Distribution of log consumption across models

bution of the model is usually not unique with perfect insurance. We therefore concentrate on the partial equilibrium parameterization with $\beta$ equal to 0.958 as in the PILE model. The last panel of Table 2 shows the main empirical difficulties of the LE model: apart from consumption dispersion and a value of $\gamma$ that are both an order of magnitude smaller than in the data or the other models, there is also a much stronger negative skewness (-3.680 vs. -0.940 in the data). The reason for this becomes clear from the histogram for log consumption in the bottom panel of Figure 3. A high consumption level when the participation constraint binds for high income individuals together with downward drift in consumption whenever the participation constraint does not bind for the low type implies bunching of all high-income individuals at the upper bound, and a distribution of consumption with finite support and a probability mass function that geometrically declines as consumption declines. 
Risk sharing in the Bewley-Aiyagari SILE and SIN economies. For the SIN economy, with a natural borrowing limit, the benchmark calibration yields a discount factor of 0.957. The standard deviation of log consumption in the stationary distribution is 1.385 , about 25 percent higher than that of earnings, while the regression coefficient of consumption changes on earnings changes is 0.361 , more than 1.6 times that in the PILE model, and higher than in the data. In the SILE model with a no-default borrowing limit the agents can only borrow up to 15 percent of their annual labour income. In contrast, the natural borrowing limit in the SIN is more than 10 times annual labour income. As a result, compared to the SIN economy, the SILE economy exhibits a lower discount factor of 0.953, smaller relative standard deviation of consumption (0.873 vs. 1.385) and more limited left-skew (0.904 vs. 1.823 ) of the stationary distribution of log consumption. The regression coefficient of income on consumption growth is now 0.406 .

The last panel of Table 2 show the results of our partial equilibrium exercise, where we set the discount factor in the SILE and SIN models to 0.958, the calibrated value in our PILE model. This has only a small effect on the standard deviation of log consumption but reduces the regression coefficient to a value of around 0.3 in both models.

In the second and third panel of Figure 3 we can see the histograms for both specifications of the self-insurance economy, corresponding to the consumption distribution in the partial equilibrium with $\beta=0.958$. The most striking difference between the two is the large number of agents at the no-default borrowing limit. Interestingly, the qualitative features of this distribution are not unlike those in our PILE model-both are a combination of a roughly bell-shaped upper part with a left tail that has bunching at a lower bound where the endogenous borrowing limit (in the SILE model) or the participation constraint (in our PILE model) are binding for low income agents. The natural limit of the SIN model, in contrast, where future consumption equals zero with strictly positive probability, is never binding for any consumer, as this would imply infinite marginal utility due to Inada conditions. In both SILE and SIN economies the distributions show a clear left skew.

Policy functions: PILE versus SILE. Since the PILE and SILE economies provide similar results, we investigate the differences in the policy functions in those two models. In Figure 4 we compare the consumption function of the agents in the PILE economy and in 
the SILE economy. We plot the consumption as a function of the financial intermediary's costs, and compare it with the consumption functions in the Bewley economy, as a function of the assets. ${ }^{17}$ Since the policy functions in our economy are a function of both $v_{1}$ and $v_{2}$, we simplify the plots by showing the policy functions for the cost-minimizing value of the deviator's utility. Specifically, let $v_{i}^{*}(v)$ be the cost minimizing deviator's promised utility if the previous period shock was $i$ and the truthteller's promised utility is $v$. That is we plot $c_{i}\left(v, v_{1}^{*}(v)\right)$ and $c_{i}\left(v_{2}^{*}(v), v\right)$ against the costs $P_{i}\left(v, v_{1}^{*}(v)\right)$ and $P_{i}\left(v_{2}^{*}(v), v\right)$ for $i=1,2$, and compare it to the consumption function $c_{i}(b)$ in the SILE economy. We see that for low and intermediate cost levels the optimal policy functions in the SILE economy are very close to the optimal policy functions in the PILE economy when the previous period shock is equal to the current period shock (e.g. $c_{1}(b)$ in the SILE economy is close to $c_{1}\left(v, v_{1}^{*}(v)\right)$ in the PILE economy). Given high persistency of the shocks, this turns out to be the quantitatively relevant case. The policy functions diverge for higher asset/cost levels, where the policy functions in the PILE economy turn out to be generally flatter than in the SILE economy, reflecting a higher degree of insurance.

\section{Effects of Interventions}

In this section, we consider the implications of two types of intervention: (i) a compression of the distribution of individual earnings, reducing the standard deviation by 10 percent, and (ii) a social insurance policy consisting of a lump-sum transfer payment financed by a proportional consumption tax. We concentrate on consumption taxes, rather than income taxes. This is because, according to Proposition 2.1, there is very little rationale for income taxes in our environment. A tax reform that increases the degree of redistribution decreases welfare. For each intervention, we compare the effect on risk sharing and also average steady state welfare in general equilibrium. Specifically, we keep the parameters for technology $(A, \theta)$ and preferences $(\sigma, \beta)$ equal to their values in the benchmark calibration of each model but change the interest rate $R$ in order to ensure market clearing. It is worth noticing that the aggregate capital stock, and hence the equilibrium wage, changes as $R$ is

\footnotetext{
${ }^{17}$ Assets in the Bewley economy are comparable to costs in our economy. They both determine the costs of delivering certain lifetime utility in a given market structure (complete markets in our economy, and incomplete markets in the Bewley economy.)
} 


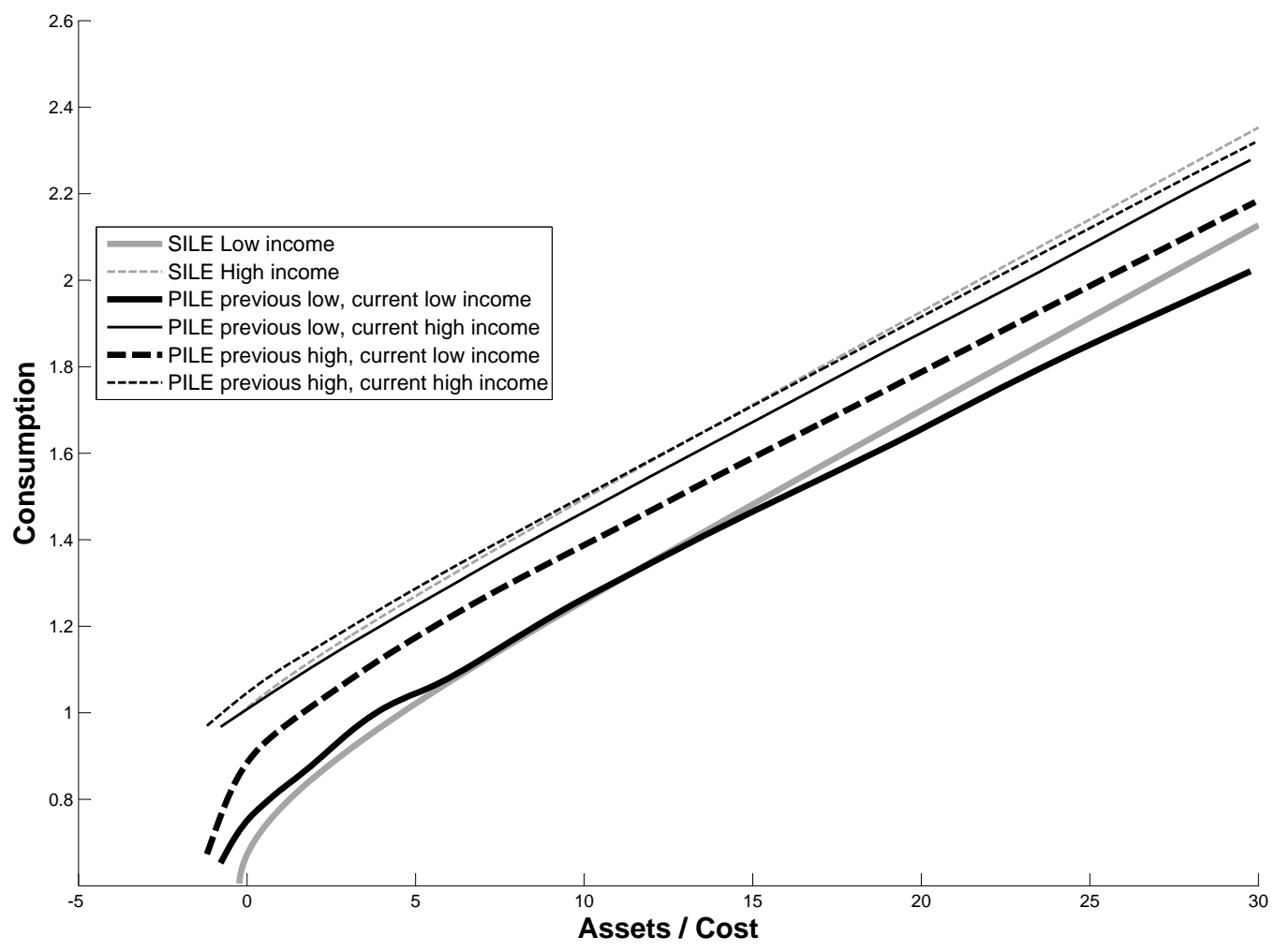

Figure 4: Policy functions in PILE and SILE economies.

adjusted. In the case of the social insurance policy, we also ensure that the transfer $s^{y}$ is such that the government budget constraint balances.

A priori, we would expect both an earnings compression and a lump-sum income transfer financed by consumption taxes to translate into less volatile consumption and thus to increase average steady state welfare. When risk sharing is limited because of frictions that inhibit information flow or contract enforcement, however, it is crucial to take into account how any intervention interacts with those frictions. The main question we ask here is therefore the following: to what extent does the intervention in question undermine private insurance, in the context of our PILE model as well as other models of risk sharing? Given that the LE economy exhibits perfect insurance in the benchmark case, we only compare the PILE economy with SILE and SIN economies. 


\subsection{Compression of the Earnings Process}

Consider the effects on the consumption distribution when income dispersion is exogenously reduced by 10 percent through a contraction in the support of labour productivity that leaves both mean productivity and transition probabilities unchanged. We take as our benchmark the income process estimated on the whole sample period, and consider the effect of a reduction in the dispersion of labour incomes as we just described. We focus on the resulting change in both the standard deviation of log consumption, and on a simple measure of aggregate welfare $\bar{c}$, equal to the constant level of consumption that yields utility equal to the average expected utility across the stationary distribution of agents. ${ }^{18}$ This measure does not take into account transitional dynamics of the consumption distribution. However, to the extent that we find that a social insurance policy delivers a welfare increase across stationary equilibria, the computed increase is likely to be a lower bound on the actual welfare increase that takes into account the transition to stationary equilibrium. This is because the social insurance policy will typically reduce the aggregate capital stock, and neglecting to take into account the transition means neglecting the welfare-raising opportunity to consume that part of the capital stock.

Table 3: Effects of income compression

\begin{tabular}{lrrr}
\hline & $\Delta \sigma_{\ln c}$ & $\Delta \bar{c}$ & $\Delta K$ \\
\hline PILE & -6.390 & 0.645 & -0.648 \\
SIN & -3.173 & 1.472 & -1.200 \\
SILE & -7.279 & 0.832 & -1.914 \\
\hline
\end{tabular}

Percentage change in the standard deviation of log consumption $\Delta \sigma_{\ln c}$, in the permanent consumption equivalent of average expected utility $\Delta \bar{c}$, and in the aggregate capital stock $\delta K$ in response to a $10 \%$ reduction in the cross-sectional income dispersion.

Table 3 presents the results of our earnings compression exercise. In line with the results in Krueger and Perri (2006), the SILE economy predicts a strong reduction in the dispersion of consumption by $7.279 \%$, about three quarters of the reduction in income dispersion. The corresponding increase in average welfare, however, is only $0.832 \%$, as the reduction in income volatility reduces precautionary savings, and thus (through a rise in the equilibrium interest rate) the capital stock, slightly. The response in the SIN economy differs from that

\footnotetext{
${ }^{18}$ That is, $U(\bar{c})=\mathbb{E} U(c)$.
} 
in the SILE model for two reasons. First, higher minimum income loosens the natural borrowing limit, which acts to spread out the stationary consumption distribution, and thus counteracts the effect of the income compression, leading to a decline in the standard deviation of log consumption of only $3.173 \%$, about half as large as in the SILE economy. Second, the reduction in interest rates is smaller in the general equilibrium of the SIN economy. Aggregate capital, and thus output and consumption, therefore falls less than in the SILE economy, implying a larger welfare increase of $1.472 \%$. The PILE model predicts fall in the dispersion of consumption of $-6.390 \%$, slightly less than in the SILE economy, and a fall in capital of $0.648 \%$, smaller than in both self-insurance economies. Welfare increases by $0.645 \%$.

\subsection{Consumption Taxes}

We now consider the effects of introducing a proportional consumption tax $s^{\mathcal{c}}$ whose revenue is used to finance a lump-sum transfer $s^{y}$. We vary the consumption tax from zero (the benchmark economy) to 50 percent. Figure 5 shows how consumption dispersion (upper panel) and average steady state welfare (lower panel) change with respect to their benchmark values $\left(s^{y}=s^{c}=0\right)$ as consumption taxes increase.

The first striking result is the similarity of the solid and dashed grey lines: changes in consumption dispersion and in average steady state welfare induced by rising consumption taxes are very similar in our PILE model compared to the SILE economy with no-default borrowing limits. Specifically, consumption dispersion falls approximately linearly in both models, with a reduction in the standard deviation of log-consumption equal to between 70 to 80 percent of that in log incomes at all tax levels. So crowding out of consumption taxes is small. This implies an also approximately linear increase in average steady state welfare, as the bottom panel of Figure 5 shows. In line with the results for the income compression, consumption dispersion falls by less in the SIN economy. However, aggregate capital and output also falls less as the equilibrium interest rates increase more slowly as taxes rise, leading to an increase in welfare that is very similar to those in the SILE and PILE economies.

It is useful to also compare our results with the results in Krueger and Perri (2011). In the 


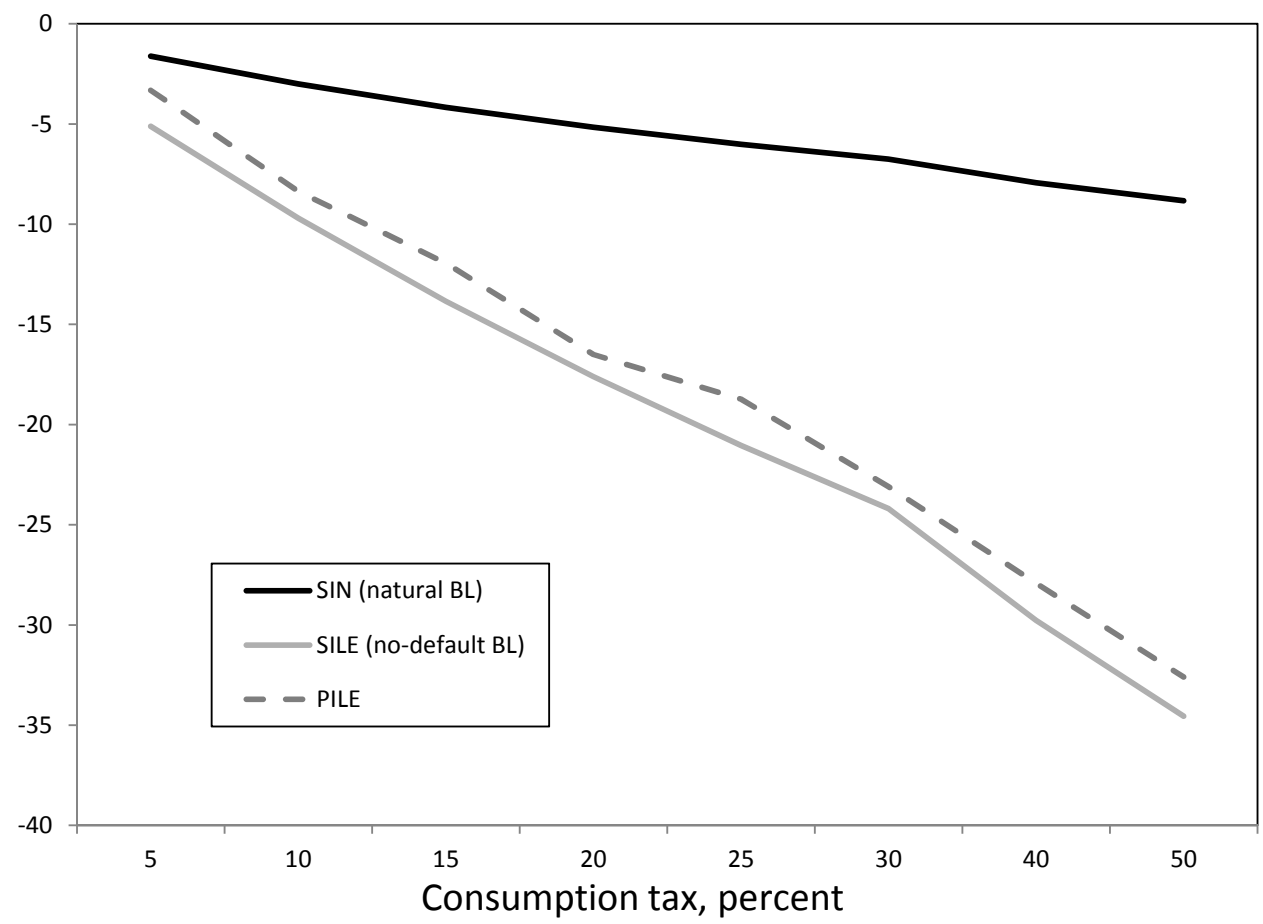

(a) Change in standard deviation of log-consumption

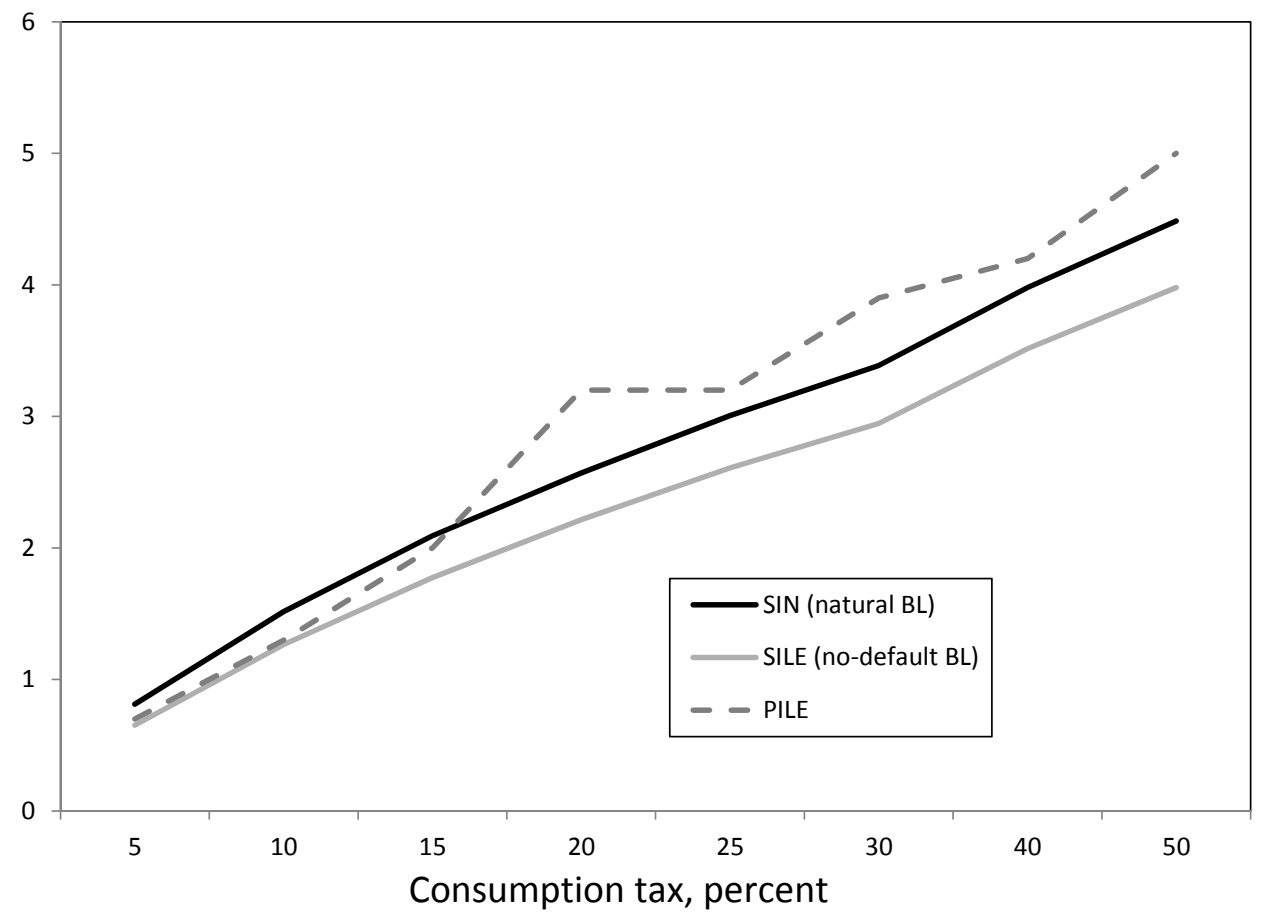

(b) Change in consumption equivalent of average steady state welfare Figure 5: The effect of increasing consumption taxes 
Krueger-Perri economy either the consumption tax or an income tax affect the equilibrium allocations in a conceptually similar way. In both cases, they only matter through the effects on the limited enforcement constraints. By making the outside option of financial autarky more attractive, and thus tightening the participation constraint, consumption and income taxes can potentially end up increasing consumption risk, crowding out private insurance more than one-for-one. In the PILE economy, in contrast, there is an additional channel through which consumption taxes affect equilibrium consumption insurance: they affect the gains from deviations, and so they affect the equilibrium insurance contract even conditional on the values of autarky. Higher consumption tax reduces the gains from deviations, and increases the efficiency of the equilibrium insurance contract. This in turn decreases consumption dispersion leading to results that are more in line with the Bewley-Aiyagari SILE economy, rather than with the Krueger-Perri LE economy.

\section{Concluding Remarks}

In this paper, we have studied the implications of a model of dynamic risk sharing under private information about earnings and limited enforcement of contracts. We find that such a model delivers observable implications that are much more palatable than those of its parent environments. Models of efficient consumption risk sharing with private information alone imply immiserization; models with limited enforcement alone imply that consumption is either constant, drifts down or leaps up. With the two frameworks combined, the implications are much more reasonable; more in line with the data and in fact rather similar to those of Bewley-Aiyagari economies.

Meanwhile, the mechanisms are of course quite different. This led us to investigate the effects of hypothetical interventions as implied by our model, and to compare them with the implications of other models of dynamic risk sharing in the literature. Our main findings were as follows. Perhaps our starkest result is that any social insurance scheme that relies on income taxes cannot work in our private information and limited enforcement (PILE) model; anything useful that such a scheme accomplishes would be undone by private insurance companies. However, funding through consumption taxes can work very well, provided that the government can observe sales. 
Moreover, we find that redistributive consumption taxes and a compression of the aftertax earnings process in our PILE model translate into falls in consumption dispersion and increases in welfare that are large and similar to those in a SILE economy. In other words, while the PILE model is pessimistic about the redistributive potential of income taxes by construction, it predicts only moderate crowding out of private insurance in response to redistributive consumption taxation or a fall in income inequality.

\section{Appendix A: Proof of Proposition 4}

Proof of Proposition 3.1. The promise keeping constraint (11), the threat keeping constraint (9) and the left hand side of the incentive compatibility constraint (8a) are all linear in $u$ and $w$. The right-hand side of (8a) is convex in $u$ and $w$ when $\delta>0$. The constraint (8b) is slack by assumption. Hence the constraints form a convex set.

Before proving Proposition 4, we show several preliminary results. The lower bound can be written as

$$
\underline{V}\left(v_{1}\right)=\min _{u, w} \pi_{21}\left(u_{1}+\beta w_{1}^{1}\right)+\pi_{22}\left(u_{2}+\beta w_{2}^{2}\right)
$$

subject to

$$
\begin{aligned}
& \quad v_{1}=\pi_{11}\left(u_{1}+\beta w_{1}^{1}\right)+\pi_{12}\left(u_{2}+\beta w_{2}^{2}\right) \\
& u_{2}+\beta w_{2}^{2} \geq \psi\left(u_{1}, \delta\right)+\beta w_{1}^{2} \\
& u_{1}+\beta w_{1}^{1} \geq \psi\left(u_{2},-\delta\right)+\beta w_{2}^{1} \\
& w_{i}^{1} \geq V_{1}^{\mathrm{AUT}} \\
& w_{i}^{2} \geq V_{2}^{\mathrm{AUT}} \\
& w_{i}^{2} \geq \underline{V}\left(w_{i}^{1}\right)
\end{aligned}
$$

The constraint (19) is obviously the promise keeping constraint for the low type, (20) and (21) are the two incentive constraints, (22) and (23) are limited enforcement constraints ${ }^{19}$, and (24) is a requirement that the continuation on the contract along the lower bound is not

\footnotetext{
${ }^{19}$ For simplicity, we set $s^{c}=s^{y}=0$ to reduce notation. The result does not depend on this assumption.
} 
below the lower bound. ${ }^{20}$ We repeat them here only for easier reading.

Standard dynamic programming arguments show that $\underline{V}$ is continuous and bounded from above by 0 and from below by $V_{2}^{\text {AUT }}$. Other properties of interest are proven in a series of lemmas.

Lemma $1 \underline{V}(v) \geq v$.

Proof. Consider a truncated problem where the agents live only for $T+1<\infty$ periods $t=0, \ldots, T$. Let $\left(u_{i, t}, w_{i, t+1}^{j}\right)$ be an allocation of the truncated problem in period $t=0, \ldots, T$, with $w_{i, T+1}^{j}=0$ by truncation. Let also $\underline{V}_{t}^{(T)}(v)$ be the lower bound of the truncated problem in period $t=0, \ldots, T$. The incentive constraint (8a) in the last period $T$ implies that

$$
u_{2, T} \geq \psi\left(u_{1, T}, \delta\right) \geq u_{1, T}
$$

Assume that $u_{i, T}$ is an allocation along the lower bound. Then

$$
\underline{V}_{T}^{(T)}(v)=u_{1, T} \pi_{21}+u_{2, T} \pi_{22} \geq u_{1, T} \pi_{1 i}+u_{2, T} \pi_{12}=v
$$

Now assume that $\underline{V}_{t+1}^{(T)}(v) \geq v$ for some $t \leq T-1$. The incentive constraint (8a) in period $t$ implies

$$
u_{2, t}+\beta w_{2, t+1}^{2} \geq \psi\left(u_{1, t}\right)+\beta w_{1, t+1}^{2} \geq \psi\left(u_{1, t}\right)+\underline{V}_{t+1}^{(T)}\left(w_{1, t+1}^{1}\right) \geq u_{1, t}+\beta w_{1, t+1}^{1} .
$$

If $u_{i, t}+\beta w_{i, t+1}^{i}$ is an allocation along the lower bound then

$$
\begin{aligned}
\underline{V}_{t}^{(T)}(v) & =\left(u_{1, t}+\beta w_{1, t+1}^{1}\right) \pi_{21}+\left(u_{2, t}+\beta w_{2, t+1}^{2}\right) \pi_{22} \\
& \geq\left(u_{1, t}+\beta w_{1, t+1}^{1}\right) \pi_{11}+\left(u_{2, t}+\beta w_{2, t+1}^{2}\right) \pi_{12}=v .
\end{aligned}
$$

By induction, $\underline{V}_{t}^{(T)}(v) \geq v$ for all $t=1, \ldots, T$. Since $T$ was arbitrary we have

$$
\underline{V}(v)=\lim _{T \rightarrow \infty} \underline{V}^{(T)}(v) \geq v
$$

\footnotetext{
${ }^{20}$ One should in principle also include a requirement that the continuation on the contract along the lower bound is not above the upper bound. That constraint will not be binding, however, and is omitted.
} 
Lemma 2 The constraint (20) is binding.

Proof. Suppose not. Assume first that $u_{1}<0$. Increase $u_{1}$ by $\epsilon_{1}>0$ and decrease $u_{2}$ by $\epsilon_{2}=\frac{\pi_{11}}{\pi_{12}} \epsilon_{1}$. The constraint (19) continues to hold. Since constraint (20) was slack, it continues to hold for $\epsilon_{1}$ small enough. Constraint (21) is relaxed, while constraints (22), (23) and (24) continue to hold. The objective function decreases by $\pi_{11}\left(\frac{\pi_{22}}{\pi 12}-\frac{\pi_{21}}{\pi 11}\right) \epsilon_{1}>0$.

If $u_{1}=0$ then increase $w_{1}^{1}$ instead of $u_{1}$, with a corresponding increase in $w_{1}^{2}$ so that $w_{1}^{2} \geq$ $\underline{V}\left(w_{1}^{1}\right)$ continues to hold. For $\epsilon_{1}$ small enough this variation again decreases the objective function. If both $u_{1}=w_{1}^{1}=0$ then the right-hand side of (8a) is zero, implying that the left-hand side $u_{2}+w_{2}^{2}$ is zero as well.

Lemma $3 w_{1}^{2}=\underline{V}\left(w_{1}^{1}\right)$.

Proof. Suppose that $w_{1}^{2}>\underline{V}\left(w_{1}^{1}\right)$. Decreasing $w_{1}^{2}$ is then feasible, and relaxes the constraint (20). Since it does not show up in any of the remaining constraints, nor the objective function, Decreasing $w_{1}^{2}$ is optimal.

\section{Proof of Proposition 4.}

The first part has been proven in Lemma 1. We now show that $\bar{V}(v) \leq \frac{\pi_{21}}{\pi_{11}} v$. Consider a solution to the problem that ignores the incentive constraints (8a). The principal assigns the lowest possible lifetime utility to a low state since, by Assumption 2, the ratio of probabilities satisfies $\frac{\pi_{21}}{\pi_{11}}<\frac{\pi_{22}}{\pi_{12}}$. Thus $u_{1}+\beta w_{1}^{1}=\frac{v}{\pi_{11}}, u_{2}+\beta w_{2}^{2}=0$, and the upper bound is then

$$
\bar{V}(v)=\pi_{21}\left(u_{1}+\beta w_{1}^{1}\right)=\frac{\pi_{21}}{\pi_{11}} v .
$$

It is easy to verify that the incentive constraint (8a) holds along this upper bound. The incentive constraint (8b) is violated along this upper bound, but adding (8b) can only decrease the upper bound. 
To show that $\underline{V}\left(V_{1}^{\mathrm{AUT}}\right)=V_{2}^{\mathrm{AUT}}$, consider the following allocation: $u_{1}=u_{2}=0$ and $w_{1}^{1}=$ $w_{2}^{2}=\frac{v}{\beta}$. This allocation is trivially incentive compatible since it is independent of the report. It is the only allocation that delivers $v_{2}=v_{1}$, and so it must be on (or below) the lower bound. However, the allocation violates (9a) at $v_{1}=V_{1}^{\mathrm{AUT}}$ since $w_{1}^{1}=\beta^{-1} V_{1}^{\mathrm{AUT}}<V_{1}^{\mathrm{AUT}}$. Hence (9a) must bind, i.e. $w_{1}^{1}=V_{1}^{\text {AUT }}$. By Lemma 2 the incentive constraint (8a) always binds along the lower bound, and by Lemma $3 w_{1}^{2}=\underline{V}\left(V_{1}^{\mathrm{AUT}}\right)$. The objective function and the promise keeping constraint (19) can be written as

$$
\begin{aligned}
\underline{V}\left(V_{1}^{\mathrm{AUT}}\right) & =\pi_{21}\left(u_{1}+\beta V_{1}^{\mathrm{AUT}}\right)+\pi_{22}\left[\psi\left(u_{1}, \delta\right)+\beta \underline{V}\left(V_{1}^{\mathrm{AUT}}\right)\right] \\
V_{1}^{\mathrm{AUT}} & =\pi_{11}\left(u_{1}+\beta V_{1}^{\mathrm{AUT}}\right)+\pi_{12}\left[\psi\left(u_{1}, \delta\right)+\beta \underline{V}\left(V_{1}^{\mathrm{AUT}}\right)\right] .
\end{aligned}
$$

This is a system of two equations in two unknowns $\underline{V}\left(V_{1}^{\mathrm{AUT}}\right)$ and $u_{1}$. Noting that $\psi\left(U\left(y^{1}\right), \delta\right)=$ $U\left(y^{2}\right)$, the system of equations is solved by $u_{1}=U\left(y^{1}\right)$ and $\underline{V}\left(V_{1}^{\mathrm{AUT}}\right)=V_{2}^{\mathrm{AUT}}$. The allocation is trivially incentive compatible as it involves no transfers. In addition, it follows that the constraint $(9 \mathrm{~b})$ is satisfied automatically since $w_{2}^{2}=w_{1}^{2}=V_{2}^{\mathrm{AUT}}$, and hence does not bind.

\section{Appendix B: Estimating the earnings process}

The parameters that characterize the income process are the variances of the shocks $\sigma_{\varepsilon}^{2}, \sigma_{x}^{2}$ and $\sigma_{\alpha}^{2}$, the autocorrelation of the persistent shock $\rho$ and the third central moments of $\alpha_{i}, x_{i, t}$ and $\varepsilon_{i, t}$. We estimate these parameters by GMM where the moments are the autocovariances $\Gamma_{k}=\mathbb{E}\left[\tilde{y}_{i, t} \tilde{y}_{i, t+k}\right]$, where $\tilde{y}_{i, t}$ is the logarithm of earnings, the $k$ th covariance is computed as the average over all possible products $\tilde{y}_{i, t} \tilde{y}_{i, t+k}$ for which data is available and $k=0,1, \ldots, 11$ as well as the following third moments:

$$
\begin{aligned}
\Delta_{0,0} & :=\mathbb{E}\left[\tilde{y}_{i, t}^{3}\right] \\
\Delta_{0,1} & :=\mathbb{E}\left[\tilde{y}_{i, t}^{2} \tilde{y}_{i, t+1}\right], \\
\Delta_{1,1} & :=\mathbb{E}\left[y_{i, t} \tilde{y}_{i, t+1}^{2}\right] .
\end{aligned}
$$

The autocovariances are geometrically smoothed as described in Table 4 . 
Table 4: Moments used in estimation

\begin{tabular}{lrrrc}
\hline & $\begin{array}{r}\text { Sample } \\
\text { moments }\end{array}$ & $\begin{array}{r}\text { Smoothed } \\
\text { moments }\end{array}$ & $\begin{array}{r}\text { Theoretical } \\
\text { moments }\end{array}$ & Number of obs. \\
$\Gamma_{0}$ & 0.1690 & 0.1690 & 0.1686 & 59550 \\
$\Gamma_{1}$ & 0.1197 & 0.1126 & 0.1135 & 37828 \\
$\Gamma_{2}$ & 0.1064 & 0.1055 & 0.1060 & 36791 \\
$\Gamma_{3}$ & 0.0958 & 0.0988 & 0.0990 & 27202 \\
$\Gamma_{4}$ & 0.0909 & 0.0926 & 0.0925 & 27178 \\
$\Gamma_{5}$ & 0.0844 & 0.0868 & 0.0865 & 22712 \\
$\Gamma_{6}$ & 0.0799 & 0.0813 & 0.0810 & 22074 \\
$\Gamma_{7}$ & 0.0745 & 0.0762 & 0.0759 & 19492 \\
$\Gamma_{8}$ & 0.0716 & 0.0715 & 0.0712 & 18061 \\
$\Gamma_{9}$ & 0.0675 & 0.0670 & 0.0668 & 15972 \\
$\Gamma_{10}$ & 0.0641 & 0.0628 & 0.0628 & 14861 \\
$\Gamma_{11}$ & 0.0601 & 0.0589 & 0.0591 & 12106 \\
$\Delta_{0,0}$ & -0.0369 & -0.0369 & -0.0369 & 59550 \\
$\Delta_{0,1}$ & -0.0181 & -0.0181 & -0.0181 & 37828 \\
$\Delta_{1,1}$ & -0.0167 & -0.0167 & -0.0167 & 37828 \\
\hline
\end{tabular}

Our GMM procedure simply involves matching these empirical moments to the theoretical moments implied by our statistical model. Our parameter estimates are $\widehat{\sigma}_{\varepsilon}^{2}=0.0157$, $\widehat{\sigma}_{x}^{2}=0.0469$ and $\widehat{\sigma}_{\alpha}^{2}=0.0132$, and $\widehat{\rho}=0.9247$. These results are very similar to those of Klein and Telyukova (2013), implying that about 64 percent of the total variance of residual log earnings is accounted for by the persistent component. For the CEX, the earnings estimation requires more elaborate techniques, because of the overlapping observations. This is discussed in Gervais and Klein (2010).

\section{Appendix C: Computing the Value Function}

To find the optimal contract, we use value function iteration with finite-element interpolation. Interpolation in this case is somewhat complicated by the fact that the state space $\mathcal{V}$ is not rectangular. Thus we cannot define a grid as a Cartesian product between two fixed one-dimensional grids. What we do instead is to define a grid for $v_{1}$, and for each point on that grid we define a grid for $v_{2}$. The total number of points is 17250 , and the range is more 
than wide enough in each dimension to cover the ergodic set as discovered in simulations. The finite-element interpolation method works as follows. First we define the elements as triangles whose vertices are the gridpoints and where the union of these triangles coincides with the convex hull of the set of gridpoints. Clearly such a triangulation is not unique. The particular triangulation that we use is that defined by Delaunay (1934). It is illustrated for a case of four gridpoints in Figure 6. We do not claim that this particular triangulation is optimal in any sense, though optimality can be established in special cases; see, for instance Chen and $\mathrm{Xu}$ (2013).

Second, we define, once and for all given the gridpoints and the triangulation, coefficients that we will need to linearly interpolate within each triangle. To see what these coefficients are, let's move one step ahead and suppose we have an arbitrary point $(x, y)$ in the domain and we want to find the interpolating value $z$ given that we know what triangle $(x, y)$ is in. Call the vertices of this triangle $\left(x_{0}, y_{0}\right),\left(x_{1}, y_{1}\right)$ and $\left(x_{2}, y_{2}\right)$ and suppose the function values at these vertices are $z_{0}, z_{1}$ and $z_{2}$. Evidently there exist scalars $t$ and $u$ such that

$$
(x, y)=\left(x_{0}, y_{0}\right)+t \cdot\left(x_{1}-x_{0}, y_{1}-y_{0}\right)+u \cdot\left(x_{2}-x_{1}, y_{2}-y_{1}\right)
$$

Figure 7 illustrates this very simple idea. Once we have found the values of $t$ and $u$, our interpolating value is of course

$$
z=z_{0}+t \cdot\left(z_{1}-z_{0}\right)+u \cdot\left(z_{2}-z_{1}\right)
$$

We need, then, an efficient way of finding $t$ and $u$ as a function of $x$ and $y$. It turns out that, for each triangle, the vector $\left[\begin{array}{ll}t & u\end{array}\right]$ is a fixed affine function of the vector $\left[\begin{array}{ll}x & y\end{array}\right]$. Thus what we need to do, once and for all given the gridpoints and the triangulation, is to compute, for each triangle, the constant term and the gradient of this affine function. Finding this constant term and this gradient requires us to invert a $2 \times 2$ matrix, but the important thing is that this is only done once for each triangle. Having computed these coefficients once and for all, finding the interpolating value at an arbitrary point is just a matter of (1) finding the right triangle and (2) evaluating an affine function. This can of course be done very quickly, and this is important because it is done many thousands of times during the value function iteration. 


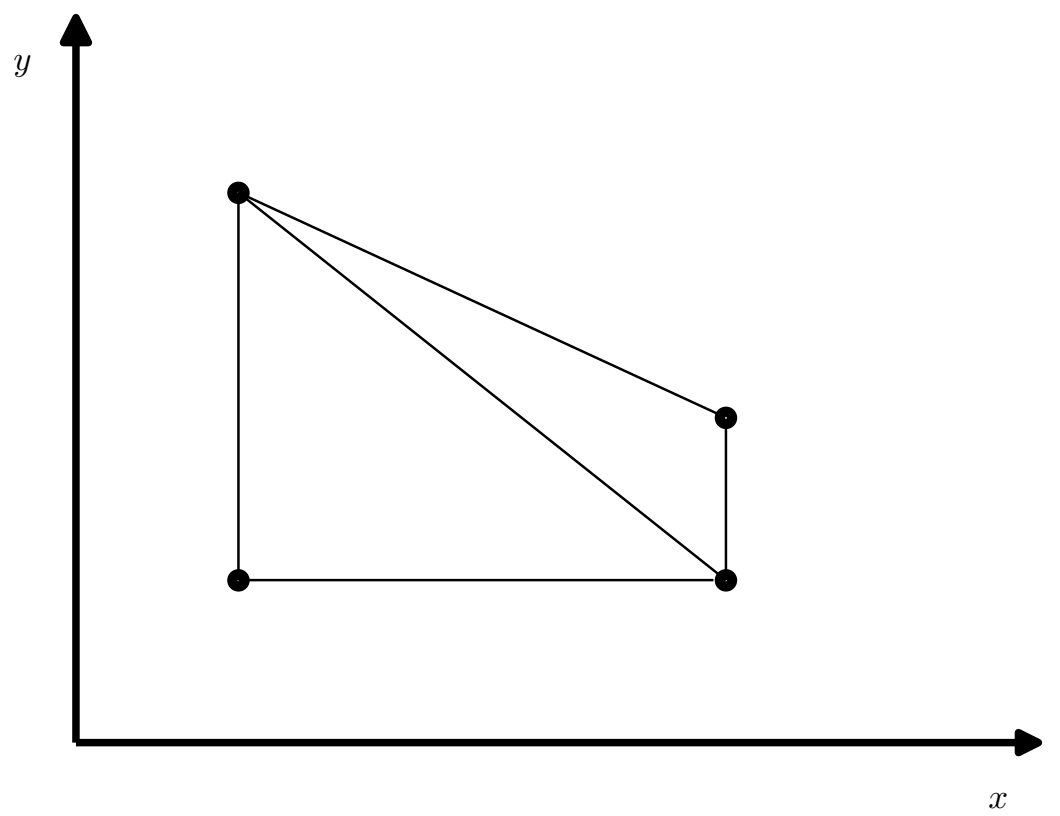

Figure 6: A Delaunay triangulation

To compute moments of the stationary distribution, we simply use the optimal allocation rule to simulate 100000 observations. To find the general equilibrium, we choose the interest rate $R$ that ensures that mean consumption is equal to available resources in a steady state, as described in Section 3.3.

The underlying assumption here is that the insurance providers own the capital. Moving to live in autarky means forgoing any access to this capital. The specific parameter values used are $\delta=.08$ and $\theta=1 / 3$.

\section{References}

Abraham, A. and E. Cárceles-Poveda (2009). Competitive equilibria with production and limited commitment. Technical report, Suny Stony Brook. 21

Aiyagari, S. R. (1994). Uninsured idiosyncratic risk, and aggregate saving. Quarterly Journal of Economics 109, 659-684. 1, 2, 3, 21

Ales, L. and P. Maziero (2009, December). Adverse selection and non-exclusive contracts. GSIA Working Papers 2010-E61, Carnegie Mellon University, Tepper School of Business. 5 


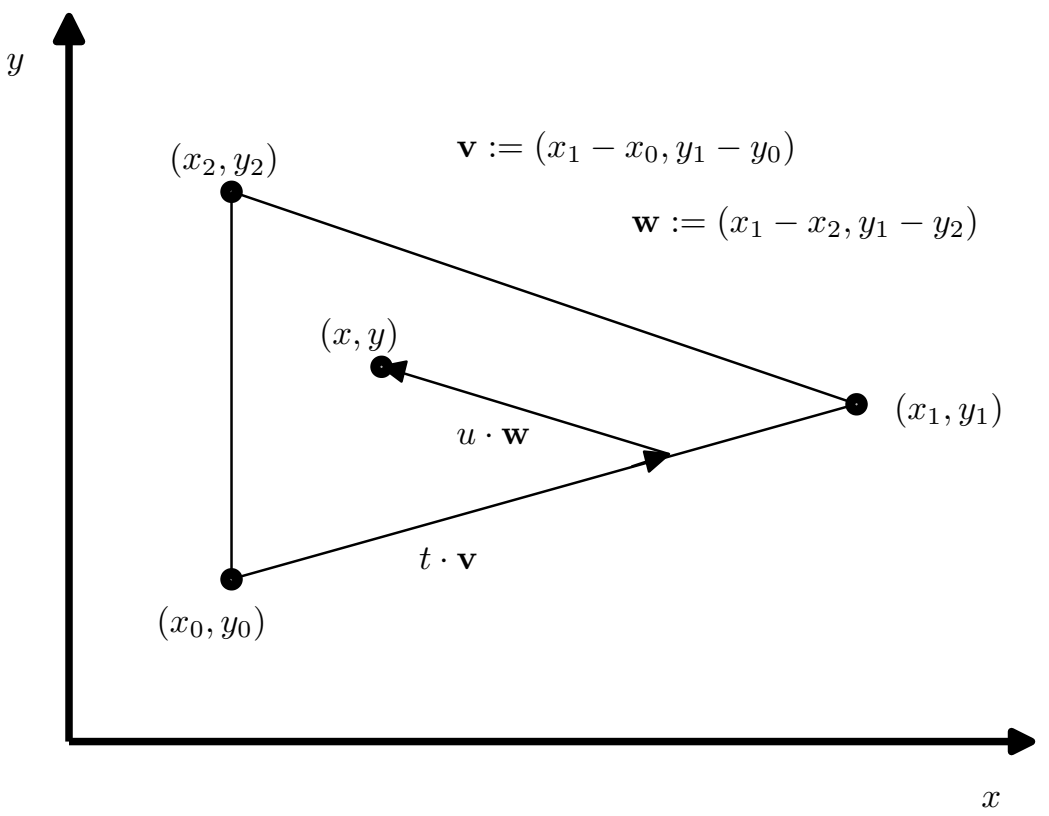

Figure 7: Linear interpolation on a triangle 
Allen, F. (1985). Repeated principal-agent relationships with lending and borrowing. Economics Letters 17(1), 27-31. 4

Attanasio, O. P. and N. Pavoni (2011). Risk sharing in private information models with asset accumulation: Explaining the excess smoothness of consumption. Econometrica 79(4), 1027-1068. 5

Battistin, E., R. Blundell, and A. Lewbel (2009). Why is consumption more log normal than income? Gibrat's law revisited. Journal of Political Economy 117, 1140-1154. 25

Bewley, T. (1977, December). The permanent income hypothesis: A theoretical formulation. Journal of Economic Theory 16(2), 252-292. 2, 3, 21

Broer, T. (2013, October). The Wrong Shape of Insurance? What Cross-Sectional Distributions Tell Us about Models of Consumption Smoothing. American Economic Journal: Macroeconomics 5(4), 107-40. 2

Brzozowski, M., M. Gervais, P. Klein, and M. Suzuki (2010). Dimensions of inequality in Canada. Review of Economic Dynamics 13, 52-75. 25

Chen, L. and J. Xu (2013). Optimal Delaunay triangulations. Journal of Computational Mathematics 22(2), 299-308. 44

Cole, H. L. and N. R. Kocherlakota (2001). Efficient allocations with hidden income and hidden storage. The Review of Economic Studies 68, 523-542. 4

Delaunay, B. (1934). Sur la sphÃ̈re vide. Izvestia Akademii Nauk SSSR, Otdelenie Matematicheskikh i Estestvennykh Nauk 7, 793-800. 44

Farhi, E. and I. Werning (2011, January). Insurance and taxation over the life cycle. NBER Working Papers 16749, National Bureau of Economic Research, Inc. 5

Fernandes, A. and C. Phelan (2000, April). A recursive formulation for repeated agency with history dependence. Journal of Economic Theory 91(2), 223-247. 4, 8, 20

Gervais, M. and P. Klein (2010). Measuring consumption smoothing in CEX data. Journal of Monetary Economics 57, 988-999. 25, 29, 30, 43

Golosov, M. and A. Tsyvinski (2007). Optimal taxation with endogenous insurance markets. Quarterly Journal of Economics 122, 487-534. 5

Golosov, M., A. Tsyvinski, and M. Troshkin (2012). Optimal dynamic taxes. Working paper, Yale University. 5

Guvenen, F. (2007). Learning your earning: Are labor income shocks really very persistent? American Economic Review 97(3), 687-712. 24

Heathcote, J., F. Perri, and G. L. Violante (2010). Unequal we stand: An empirical analysis of economic inequality in the united states: 1967-2006. Review of Economic Dynamics 13(1), 15-51. 22, 24 
Huggett, M. (1993). The risk free rate in heterogeneous-agents, incomplete insurance economies. Journal of Economic Dynamics and Control 17(5/6), 953-970. 3, 21

Huggett, M. (1997). The one-sector growth model with idiosyncratic shocks: Steady states and dynamics. Journal of Monetary Economics 39(3), 385-403. 3

Kapička, M. (2013). Efficient allocations in dynamic private information economies with persistent shocks: A first-order approach. The Review of Economic Studies 80, 1027-1054. 5

Klein, P. and I. Telyukova (2013). Measuring high-frequency income risk from lowfrequency data. Journal of Economic Dynamics and Control 37(3), 535-542. 24, 43

Krueger, D. and F. Perri (2004). Understanding consumption smoothing: Evidence from US consumer expenditure data. Journal of the European Economic Association 3(2-3), 340-350. 21

Krueger, D. and F. Perri (2006). Does income inequality lead to consumption inequality? evidence and theory. Review of Economic Studies 73(1), 163-193. 2, 3, 9, 21, 30, 35

Krueger, D. and F. Perri (2011). Public versus private risk sharing. Journal of Economic Theory 146(3), 920-956. 2, 3, 9, 13, 36

Krueger, D. and H. Uhlig (2006). Competitive risk sharing contracts with one-sided commitment. Journal of Monetary Economics 53(7), 1661-1691. 3, 21

Manovskii, I., D. Hryshko, and M. Daly (2014). Reconciling Estimates of Income Processes in Growth Rates and Levels. Manuscript. 24

Mirrlees, J. A. (1971). An exploration in the theory of optimum income taxation. The Review of Economic Studies 38, 175-208. 5

Pavan, A., I. Segal, and J. Toikka (2014). Dynamic mechanism design: A myersonian approach. Econometrica 82(2), 601-653. 5

Thomas, J. and T. Worrall (1990). Income fluctuations and asymmetric information: An example of a repeated principal-agent problem. Journal of Economic Theory 51(2), 367-390. 4,17

Zhang, H. H. (1997). Endogenous borrowing constraints with incomplete markets. Journal of Finance 52(5), 2187-2209. 26, 27 